\title{
II. Zentralismus versus Föderalismus: Die Deutsche Zentralverwaltung für Justiz und die Landes- bzw. Provinzialjustizverwaltungen (1945-1947)
}

\section{Der Konflikt um das Weisungsrecht und das Statut der DJV $1945 / 46$}

Bereits vor Erlaß des Befehls zur Errichtung von Zentralverwaltungen waren in der SBZ sowohl von der sowjetischen Militäradministration als auch von den kommunistischen Remigranten in den Gruppen Ulbricht, Ackermann und Sobottka die Weichen in Richtung auf Wiederbelebung des deutschen Föderalismus gestellt worden. Die SMAD richtete mit Befehl Nr. 5 vom 9. Juli 1945 fünf regionale Militäradministrationen ein „zwecks Verwaltung der Provinzen und zur Sicherstellung der Kontrolle über die Arbeit der örtlichen Organe der Selbstverwaltung"1. Parallel dazu entstanden unter maßgeblicher Mitwirkung der deutschen Kommunisten aus Moskau auf deutscher Seite Provinzial- und Landesverwaltungen, die von der sowjetischen Besatzungsmacht am 4. und 16. Juli 1945 bestätigt wurden ${ }^{2}$. Die Neugründung der Länder und Provinzen ${ }^{3}$ erfolgte wohl primär aufgrund der pragmatischen Überlegung, in relativ kurzer Zeit in der SBZ eine funktionstüchtige Verwaltungsstruktur zu errichten. Übergeordnete deutschlandpolitische Zielsetzungen waren demgegenüber sekundär, auch wenn mit der föderalen Struktur die Gemeinsamkeit mit den Westalliierten demonstriert und eine günstige Ausgangsbasis für sowjetische gesamtdeutsche Ambitionen geschaffen wurde ${ }^{4}$. Daß die Besatzungsmacht das Schwergewicht der Verwaltung in ihrer Zone zunächst auf die Regionen legen wollte, verdeutlicht der Erlaß des Befehls Nr. 110 vom 22. Oktober 1945, in dem ,in Anbetracht des gegenwärtigen Fehlens einer zentralen deutschen Regierung" den Provinzial- und Landesverwaltungen das Recht eingeräumt wurde, Gesetze und Verordnungen mit Gesetzeskraft zu erlassen, sofern diese nicht den legislativen Akten des Kontrollrats oder der sowjetischen Militärverwaltung widersprachen ${ }^{5}$.

1 Befehl Nr. 5 vom 9. 7. 1945 in: Faschismus. Falsche und echte Befreier, S. 135 f.

2 Vgl. Mitteilung über die Bestätigung der Provinzialverwaltung Brandenburg und der Landesverwaltungen Mecklenburg und Sachsen, 4. 7. 1945, und Mitteilung über die Bestätigung der Provinzialverwaltung Sachsen und der Landesverwaltung Thüringen, in: Um ein antifaschistisch-demokratisches Deutschland, S. $82 \mathrm{f}$., $94 \mathrm{f}$.

3 Deren Umfang und Grenzen waren gegenüber dem Vorkriegsstand insbesondere durch die Abtrennung der deutschen Ostgebiete verändert worden: siehe Hajna, Länder, S. $54 \mathrm{f}$.

4 Vgl. Fait, Föderalismus, S. 12; Mielke, Auflösung, S. $21 \mathrm{f}$.

5 Gedruckt in: Um ein antifaschistisch-demokratisches Deutschland, S. $183 \mathrm{f}$. 
Bereits vor Erlaß des Befehls kam es aufgrund ungeregelter Kompetenzabgrenzungen zu Konflikten zwischen einzelnen Länderverwaltungen und den mit gesamtzonalen Leitungsaufgaben betrauten Zentralverwaltungen. Während letztere für sich ein geradezu selbstverständliches Weisungsrecht gegenüber den Fachverwaltungen auf der regionalen Ebene reklamierten ${ }^{6}$, waren die Provinzial- und Landesverwaltungen darauf bedacht, den ihnen von der sowjetischen Militäradministration eingeräumten Spielraum zu erhalten, und wehrten sich gegen Eingriffe aus Berlin?. Hinzu kam, daß der Präsident der DJV von der Notwendigkeit einer Zentralisierung des Justizwesens überzeugt war: „Zentralisierung der Gesetzgebung und Gesetzesauslegung“, so das Fazit eines auf Äußerungen Schiffers beruhenden Artikels in der „Täglichen Rundschau“, „ist die Voraussetzung aller Ordnung, besonders jeder normal funktionierenden Wirtschaft. So dient auch die Tätigkeit der Justizverwaltung der Entwicklung der lebenswichtigen Wirtschaft in der sowjetischen Besatzungszone Deutschlands."8 Schiffers Eintreten für eine zentralisierte Justizverwaltung ist jedoch nicht nur auf die Erfordernisse der unmittelbaren Nachkriegszeit, sondern auch auf seine Vorstellung zurückzuführen, daß eine Neuorganisation des Justizwesens in „engem und bedeutungsvollem $\mathrm{Zu}$ sammenhange" mit dessen "Verreichlichung" stehe. Denn „Verreichlichung" bedeutete Rationalisierung und diente somit dem Abbau der „Hypertrophie des Rechts"9. Die Beweggründe Schiffers, "gegenüber den Landes- und Provinzialverwaltungen den Reichsminister a.D. etwas stark heraus[zukehren]"10, sind daher rational erklärbar und beruhen keineswegs auf Eitelkeit und Überheblichkeit.

Eine erste Möglichkeit, die Suprematie der DJV gegenüber den Landesjustizverwaltungen geltend zu machen, ergab sich für Schiffer aus SMAD-Befehl Nr. 49 vom 4. September 1945, der den „Direktor der zentralen deutschen Justizverwaltung" mit der Reorganisation der deutschen Gerichte beauftragte ${ }^{11}$. Die Angestellten der Zentralen Justizverwaltung, die daraufhin im September und Oktober die Landes- und Provinzialverwaltungen aufsuchten, reklamierten dabei für Schiffer das - in Befehl Nr. 49 nicht angesprochene - Recht, die leitenden Richter und Staatsanwälte zu bestellen. In diesem Sinne bat Rosenthal-Pelldram Oberlandesgerichtspräsident Arno Barth in Thüringen, den Vizepräsidenten seines Gerichts „nur im Einvernehmen mit dem Herrn Reichsjustizminister Dr. Schiffer zu [ernennen], der sich vorbehalten habe, derartige, wie überhaupt prominente Stellungen selbst nach Anhörung der Beteiligten zu besetzen"12. Während in Thüringen nach dem in der DJV vorliegenden Bericht gegen diese Äußerung keine Ein-

${ }^{6}$ Dies galt beispielsweise auch für die Zentralverwaltung für Umsiedler, siehe Schwartz, Zusammenbruch, S. $60 \mathrm{f}$.

7 Vgl. Merker, Zentralverwaltungen, S. $120 \mathrm{f}$.

8 „Keine Kluft mehr zwischen Volk und Recht!“ Besuch in der Deutschen Justizverwaltung, in: Tägliche Rundschau, 20.9.1945.

9 Vgl. Schiffer, Deutsche Justiz, 1. Aufl., S. 355-364, Zitat S. 355.

10 Anders, Demokratisierung, S. 36; vgl. auch Amos, Justizverwaltung, S. $38 \mathrm{f}$.

11 Gedruckt in: Um ein antifaschistisch-demokratisches Deutschland, S. 142 f., hier 143. Zur Durchführung des Befehls siehe vor allem Kap. A.III. Die Leiter der Zentralverwaltungen hießen anfangs auch „Direktor“.

12 Besprechung mit OLG-Präsident Barth am 24. 9. 1945, in: Bericht der Delegation nach Thüringen, o.D., BAB, DP1 VA Nr. 6, Bl. 21. 
wände erhoben wurden, wies der Präsident der brandenburgischen Provinzialverwaltung, Carl Steinhoff, Schiffers Ansicht, daß „das Ernennungsrecht hinsichtlich der höheren Beamten“ das „Kernstück der ihm [...] übertragenen Justizhoheit“ bilde, scharf zurück ${ }^{13}$. In der Provinz Sachsen wurde Ende September dem Vertreter der DJV entgegengehalten, „daß die Ernennung der Beamten, auch des höheren Dienstes, wohl so lange bei der Provinzialregierung verbleiben werde, als die Provinz die Kosten trage" 14 . Vor diesem Hintergrund betonte Rosenthal-Pelldram am 4. Oktober in Halle gegenüber Präsident Erhard Hübener, „daß die Ausübung der Justizhoheit bei dem Leiter der Deutschen Zentralen Justizverwaltung liege, so daß Herr Reichsminister Dr. Schiffer ausschließlich für die Gesetzgebung, die Ernennung und Entlassung der Beamten sowie die Zulassung zur Rechtsanwaltschaft zuständig sei“"15.

Diese und andere Widerstände aus den Landes- und Provinzialverwaltungen veranlaßten Schiffer am 30. Oktober zu einem längeren Schreiben an den Chef der SMAD-Rechtsabteilung, in dem er - unter Rückgriff auf die Ausarbeitungen seiner Abteilungsleiter ${ }^{16}$ - die Aufgaben der DJV eingehend darlegte, um eine Klärung des Verhältnisses zu den regionalen Justizverwaltungen zu erreichen. Er unterteilte die Tätigkeit der DJV in vier Arbeitsbereiche: die Ausführung von SMAD-Befehlen, die Erfüllung der überregionalen Aufgaben der Rechtspflege, die Unterstützung der SMAD-Rechtsabteilung bei der Kontrolle der Länderjustiz und die Förderung der Arbeit der Landes- und Provinzialjustizverwaltungen. Schiffer versuchte an erster Stelle das elementare sowjetische Interesse an der Ausführung von Befehl Nr. 49 in seinem Sinne zu nutzen, indem er vor allem in diesem Zusammenhang „ein klares Weisungsrecht“ forderte. Denn nur so könne eine sinnvolle Reorganisation des Gerichtswesens sowie eine „einheitliche politische Überwachung des Personalbestandes" erfolgen. Damit leitete er über zum zweiten Aufgabenfeld, in dem er ebenfalls zentrale Regelungen für erforderlich hielt: Denn bei der Ernennung der Justizbediensteten sei eine „der Rechtspflege abträgliche[.] Bevorzugung partikularer Gesichtspunkte" zu verhindern, die Ausbildung der Laienrichter „nach einheitlichen Gesichtspunkten “ müßte gewährleistet, die Anerkennung der DJV als gesetzgeberischer Instanz erreicht und "einheitliche Richtlinien für die Praxis der Gerichte" sowie für die Reform des Strafvollzugs müßten durchgesetzt werden. Hier ging es also um das Reformprogramm Schiffers, dessen Verwirklichung er angesichts partikularistischer Tendenzen gefährdet sah. Für das dritte Arbeitsgebiet schließlich, die Überprüfung der Gerichtstätigkeit durch die DJV, verlangte er lediglich „Kontrollbefugnisse, die gegenüber den Provinzial- und Landesverwaltungen klargestellt sein müssen“17.

Bevor die SMAD-Rechtsabteilung auf das Schreiben Schiffers antwortete, fand am 13. und 14. November 1945 eine Beratung der Präsidenten der Zentral-, Lan-

13 Vermerk Georg Remaks, 26. 9. 1945, BAB, DP1 VA Nr. 2, Bl. $36 \mathrm{f}$.

14 Bericht von Lentz über die Dienstreise in den Oberlandesgerichtsbezirk Naumburg vom 21.27. 9. 1945, ebenda, Bl. 38-46, hier 45.

15 Bericht über die Reise nach Halle, Leipzig und Dresden vom 4.-6.10.1945, ebenda, Bl. 57-62, hier 61.

16 Siehe Kap. A.I.3.

17 Chef der DJV an Chef der SMAD-Rechtsabteilung, 30. 10. 1945, BAB, DP1 VA Nr. 2, Bl. 85-94. Schreiben teilweise zit. bei Lorenz, Zentralverwaltung, S. 143. 
des- und Provinzialverwaltungen in Berlin statt. Bei dieser Gelegenheit beschwerten sich die Präsidenten aus Erfurt, Dresden und Schwerin über Eingriffe der Zentralverwaltungen in die Landesverwaltungen ${ }^{18}$. Schukow stellte daraufhin klar, daß „das Schwergewicht der Arbeit bei den Landes- und Provinzialverwaltungen“ liege, während die Zentralverwaltungen für „Planungs- und Lenkungsaufgaben“ sowie die Unterstützung der SMAD verantwortlich seien; nur „auf einzelnen Gebieten, wie Post und Eisenbahn“, komme ihnen eine „unmittelbare zentrale Verwaltungstätigkeit“ $\mathrm{zu}$, im übrigen sollten sie aber ,in die Tätigkeit der Landesverwaltungen nicht eingreifen und diesen keine Befehle erteilen"19. Damit hatte er, von einigen Ausnahmen abgesehen, ein Weisungsrecht der Zentralverwaltungen gegenüber den Ländern und Provinzen ausgeschlossen. Es überrascht daher nicht, daß Karassjow noch am 14. November Schiffer ermahnte, „daß jede von Ihnen durchgeführte Maßnahme diese oder jene Provinz betreffend, mit den örtlichen Verwaltungsorganen vereinbart werden muß“. Und er fuhr fort: „Die Methode des Diktats, welche sich nicht auf die reale Kenntnis der örtlichen Verhältnisse stützt, ergibt nicht immer positive Resultate. “20 Dies bedeutete zwar eine Stärkung der regionalen Justizverwaltungen, ließ jedoch deren Verhältnis zur Zentralverwaltung ungeklärt. Denn die SMAD sprach ihr nach wie vor „Planungs- und Lenkungsaufgaben" $\mathrm{zu}$, ohne genauer zu spezifizieren, auf welchen Gebieten sie tätig werden und mit welchen Mitteln sie ihrem Lenkungsanspruch Geltung verschaffen sollte.

Da somit „die staatsrechtliche Stellung der Zentralverwaltungen weder durch gemeinsame Statuten noch durch andere übergreifende Organisationsregelungen einheitlich und abschließend bestimmt" war ${ }^{21}$, ließ Schiffer auf der Grundlage seines Schreibens vom 30. Oktober ein Statut für seine Zentralverwaltung ausarbeiten. An dem im November 1945 entstandenen „Vorläufigen Statut“ der DJV22 fällt auf, daß zwar nicht mehr von einem „Weisungsrecht“ gegenüber den Justizabteilungen die Rede war, jedoch unterhalb dieser Schwelle nach wie vor sehr weitgehende Rechte für die DJV reklamiert wurden. Sie stellte sich als unverzichtbares Bindeglied zwischen dem Alliierten Kontrollrat bzw. der SMAD auf der einen und den Gerichten und Staatsanwaltschaften auf der anderen Seite dar; damit bestand sie auf einem direkten Zugang zu den Justizbehörden, ohne die Verpflich-

18 Niederschrift über die Beratung der Deutschen Verwaltung für Arbeit und Sozialfürsorge in: Merker, Beratung, S. 8 f.

19 Ebenda, S. 9; Bericht des Präsidenten der Landesverwaltung Sachsen, Dr. Rudolf Friedrich, auf einer Sitzung des Präsidiums der Landesverwaltung über die Beratung bei der Sowjetischen Militäradministration in Deutschland am 13. und 14.11. 1945, in: Um ein antifaschistisch-demokratisches Deutschland, S. $205 \mathrm{f}$. Vgl. zu der Sitzung auch die Niederschrift von Wilhelm Höcker, ebenda, S. 199-205.

20 Chef der SMAD-Rechtsabteilung an Chef der DJV, 14. 11. 1945, BAB, DP1 VA Nr. 2, Bl. 102; zit. bei Lorenz, Zentralverwaltung, S. 143. Zum Briefwechsel Schiffer-Karassjow vgl. auch Anders, Demokratisierung, S. 37.

21 So zutreffend Merker, Zentralverwaltungen, S. 103.

22 Vollständig gedruckt bei Amos, Justizverwaltung, S. 218-220. Amos datiert das Dokument auf „Ende November/Anfang Dezember“ (S. 36), ohne dies belegen zu können. Merker, Zentralverwaltungen, Anmerkungen, S. 34, datiert das Statut auf November 1945; ebenso Anders, Demokratisierung, S. 35. Nach Nikitin, Sowjetische Militäradministration und die Justiz (Manuskript), S. 2, und Bordjugov, Rechtsabteilung, S. 74, wurde das vorläufige Statut am 6.12. 1945 vom Obersten Chef der SMAD in Übereinstimmung mit dem sowjetischen Außenministerium verabschiedet. 
tung, die Landesjustizabteilungen einzuschalten. Zudem schrieb die DJV sich eine wesentliche Koordinationsaufgabe zu: Sie wollte die Einheitlichkeit der Gesetzgebung gewährleisten, indem sie Ratschläge und Empfehlungen an die Landesund Provinzialjustizverwaltungen bei der Ausarbeitung neuer Gesetze gab und bei der SMAD gegen Rechtsakte Einspruch erhob, die „mit den Grundsätzen der Demokratie" sowie den Maßnahmen des Kontrollrats und der SMAD nicht im Einklang standen. Des weiteren beharrte sie unter anderem auf einem Lenkungsund Kontrollanspruch gegenüber den Landesjustizabteilungen, gegenüber den Gerichten und Staatsanwaltschaften sowie einer „Dienstaufsicht über den Personalbestand der Gerichte, Staatsanwaltschaften, Rechtsanwaltschaften, Notariate und Gerichtsvollzieher durch die Oberlandesgerichtspräsidenten und Generalstaatsanwälte". Auch an zwei weiteren Stellen im Statut sprach sie sich wesentliche Kompetenzen bei der Personalpolitik zu: Erstens führe sie die „Entfernung faschistischer Elemente aus der Justiz durch“ und ziehe „neue Kräfte aus den demokratischen Volksschichten zum Justizdienst heran“; zweitens ernenne der Chef der DJV neben den Angestellten seiner Verwaltung auch „die Präsidenten und Richter der Oberlandesgerichte, die Landgerichtspräsidenten, die Generalstaatsanwälte bei den Oberlandesgerichten und ihre Vertreter sowie im sowjetischen Sektor Berlins die Oberstaatsanwälte bei den Amtsgerichten“.

Diese Aufgabenbeschreibung enthielt kaum weniger Kompetenzen für die DJV als das Schreiben von Ende Oktober; unklar blieb freilich die Rechtsverbindlichkeit des "vorläufigen Statuts“, das zur Bestätigung in Moskau vorgelegt wurde ${ }^{23}$. $\mathrm{Da}$ eine Antwort von dort anscheinend nicht eintraf, entschied sich die SMAD für eine Zwischenlösung. Major Nikolajew teilte am 22. Januar mit, „daß das Statut zwar fürs erste bloß als vorläufiges zu bezeichnen sei, daß es aber von Marschall Schukow bestätigt, daher schon jetzt anzuwenden und auch den Präsidenten der Provinzen und Länder mitzuteilen sei“ ${ }^{24}$. Es scheint daher, daß die unklare Kompetenzverteilung zwischen der Zentrale und den Ländern und Provinzen auch auf Kommunikationsprobleme zwischen Moskau und der Militärverwaltung in Berlin zurückzuführen war. Schiffer konnte zwar die Billigung der SMAD als Erfolg verbuchen; aber ein "vorläufiges Statut" war angesichts starker, selbstbewußter Landesverwaltungen nur von begrenztem Wert. Dies zeigte sich an den Reaktionen des thüringischen Präsidenten Rudolf Paul und seines brandenburgischen Kollegen Steinhoff auf das DJV-Statut, das ihnen, wie allen anderen Landes- und Provinzialpräsidenten, am 26. Januar 1946 übersandt worden war ${ }^{25}$. Sie protestierten bei den Militärverwaltungen in Erfurt und Potsdam gegen den mit dem Statut geplanten faktischen Entzug der Justizverwaltung zugunsten der Berliner Zentrale ${ }^{26}$. Steinhoff wies darüber hinaus in einem Schreiben an Schiffer die Lenkungs- und Kontrollansprüche der DJV über die Justizabteilung der Provinzialverwaltung sowie über Gerichte und Staatsanwaltschaften ebenso zurück wie de-

23 Vermerk über eine Besprechung Nikolajews mit Kleikamp am 12. 1. 1946, BAB, DP1 SE Nr. 3561.

24 Vermerk über das Ferngespräch mit Major Nikolajew am 22.1. 1946, BAB, DP1 VA Nr. 6410, Bl. 331.

25 Chef der DJV an die Präsidenten der Länder und Provinzen, 26. 1. 1946, BAB, DP1 VA Nr. 2, Bl. 140.

26 Zur Reaktion Pauls siehe Heil, Verwaltungsgerichtsbarkeit, S. 155. 
ren Dienstaufsichtsrecht über den Personalbestand und deren Ernennungsrecht hinsichtlich der leitenden Justizangestellten. Denn damit, so Steinhoff, würde „den Provinzen und Ländern die Justizhoheit praktisch völlig aus der Hand genommen“. Für die Beibehaltung der föderalen Strukturen sprach seiner Meinung nach nicht nur die bewährte, historisch gewachsene Kompetenzaufteilung zwischen Reich und Ländern, sondern auch die den Nachkriegsbedingungen entsprechende Praxis, die einer Zentralisierung entgegenstünde. Schließlich widersprach seiner Meinung nach das Statut den verbindlichen Ausführungen Schukows vom 13./14. November 194527. Obgleich die DJV der SMAD-Rechtsabteilung darüber berichtete28, klärte Karlshorst das Problem nicht.

Das Statut der DJV behielt vielmehr seinen vorläufigen Charakter. Wenngleich Karassjow am 8. Februar Schiffer zusagte, daß „in allernächster Zeit“ die Militärverwaltung Abschriften des Statuts ,an alle Organe der Selbstverwaltungen“ verteilen würde 29 , blieb die Durchsetzung der Kompetenzen der Zentralverwaltung schwierig, da dessen Bestätigung nicht erfolgte ${ }^{30}$. Offensichtlich war die SMADRechtsabteilung, die bereits im Januar 1946 die DJV angehalten hatte, „die Leitung des ganzen Gerichtswesens in der sowjetischen Okkupationszone stärker in ihre Hand [zu] nehmen" 31 , durchaus gewillt, ihre Zustimmung zu erteilen; es scheint jedoch, daß eine übergeordnete Stelle den rechtlich unklaren Schwebezustand der DJV zwischen der SMAD und den Regionalverwaltungen bevorzugte. Denn obwohl nach einigen Änderungen des Dokuments zugunsten der Länder im Herbst 1946 am 19. September Major Nikolajew die Absicht bekundete, „das Statut als endgültiges zu bestätigen und drucken zu lassen", und am 22. Oktober Oberstleutnant Jakupow mitteilte, „der Entwurf des neuen Statuts läge augenblicklich beim Obersten Chef der SMAD zur Bestätigung und würde gleich nach der Bestätigung der Justizverwaltung zugehen" ${ }^{32}$, änderte sich nichts an dem für die DJV unbefriedigenden Zustand. Dies legt die Vermutung nahe, daß trotz entsprechender Bemühungen der Rechtsabteilung die SMAD-Spitze eine Zentralisierung der zonalen Verwaltung in Berlin zum damaligen Zeitpunkt - möglicherweise aus deutschlandpolitischen Überlegungen heraus - für inopportun hielt. Das Verhältnis zwischen der Zentralverwaltung und den Landesjustizverwaltungen blieb damit zunächst in der Schwebe.

27 Präsident der Provinzialverwaltung Mark Brandenburg an Chef der DJV, 14. 2. 1946, BAB, DP1 VA Nr. 2, Bl. 6-8.

28 Vgl. Entwurf eines Schreibens an die SMAD-Rechtsabteilung, 16. 3. 1946, ebenda, Bl. 5.

29 Aktenvermerk über die Besprechung zwischen Schiffer und Karassjow am 8. 2. 1946, BAB, DP1 VA Nr. 11, Bl. 186.

30 Unzutreffend ist die Behauptung Heils, Verwaltungsgerichtsbarkeit, S. 155, alle Länder außer Thüringen hätten bis August 1946 das Statut anerkannt.

31 Vermerk über eine Besprechung Nikolajews mit Kleikamp am 12. 1. 1946, BAB, DP1 SE Nr. 3561.

32 Aktenvermerk über die Besprechung zwischen Nikolajew und Schiffer am 19.9. 1946, Aktenvermerk vom 22. 10. 1946, BAB, DP1 VA Nr. 11, Bl. 68, 77. Zu den Änderungen des Statuts vgl. den nächsten Abschnitt. 


\section{Die mißlungenen Versuche zur Vereinheitlichung der Justizabteilungen}

Als die Diskussion um die Gültigkeit des Statuts noch in vollem Gang war, eröffnete sich für die DJV eine weitere Chance, ihre Vorstellungen eines weitgehend von der Zentrale aus organisierten Justizwesens zu verwirklichen. Denn am 28. Februar 1946 verlangte Nikolajew angesichts der großen Unterschiede zwischen den regionalen Justizverwaltungen „eine schriftliche Äußerung darüber, wie die Justizabteilungen in den Regierungen der Länder und Provinzen einheitlich zu gestalten seien“. Gleichzeitig wandte er sich "gegen die übertriebene Ausstattung und Zuständigkeit der Justizabteilungen“ und wünschte „selbst den Schein eines Ministeriums vermieden zu sehen “33. Damit erhielt Schiffer die Möglichkeit, maßgeblichen Einfluß auf Aufbau, Umfang und Kompetenzen der Landesjustizverwaltungen auszuüben. Der sowjetische Wunsch nach möglichst kleinen Verwaltungsapparaten kam seinen Vorstellungen entgegen: Denn er hoffte, auf diese Weise eine für die DJV drohende Konkurrenz in Gestalt mächtiger Landesjustizministerien zu verhindern, und ihm erschien dadurch der Weg frei, wesentliche Teile der Justizverwaltung - insbesondere der Personalverwaltung - bei den Oberlandesgerichten und Generalstaatsanwaltschaften anzusiedeln. Damit knüpfte er nicht nur an die traditionelle deutsche Justizverwaltung an, die auch in Westdeutschland wiederbelebt wurde ${ }^{34}$; er beabsichtigte auch, sein im vorläufigen Statut festgelegtes Dienstaufsichtsrecht über das Justizpersonal mittels der von ihm ernannten Oberlandesgerichtspräsidenten und Generalstaatsanwälte durchzusetzen.

Wie Schiffer Anfang März feststellen mußte, war die Entwicklung in den Ländern und Provinzen nicht nur sehr unterschiedlich, sondern auch konträr zu seinen Vorstellungen verlaufen. Ein erster Bericht beklagte deren Neigung, „die Rolle souveräner Staaten zu spielen“. In dieser Eigenschaft hatten einige Justizabteilungen nach Auffassung der DJV „in einem ersichtlich über die gedachten Grenzen ihrer Kompetenz hinausgehenden Maße gesetzgeberische Arbeiten durchgeführt" und die Verwaltung auf Kosten der Oberlandesgerichtspräsidenten und Generalstaatsanwälte „in ihrem eigenen Bereich zentralisiert“35. Dies traf auf Sachsen, Mecklenburg-Vorpommern und Brandenburg zu, während in Thüringen und der Provinz Sachsen die Oberlandesgerichtspräsidenten ihre Verwaltungsbefugnisse weiter wahrnahmen. Die DJV schlug daher der SMAD-Rechtsabteilung am 8. März vor, die Kompetenzen der Justizabteilungen auf die Erfüllung von Aufgaben „im Rahmen der örtlichen Verwaltung“ und die „Unterrichtung und Unterstützung der Deutschen Justizverwaltung “ zu beschränken und die Oberlandesgerichtspräsidenten und Oberstaatsanwälte als „die berufenen Organe der Deutschen Justizverwaltung zur Erzielung einer gleichmäßigen Praxis der Gerichte und Staatsanwaltschaften" anzusehen. Vier Referate - 1. Gesetzgebung,

33 Aktenvermerk über die Erklärung Nikolajews, 28. 2. 1946, ebenda, Bl. 29. Vgl. dazu Lorenz, Zentralverwaltung, S. 150.

34 Vgl. für die britische Zone Wenzlau, Wiederaufbau, S. $83 \mathrm{ff} ., 159 \mathrm{f}$.

35 Erster Vorentwurf. Betr.: Stellung der Justizabteilungen der Länder und Provinzen, 4. 3. 1946, BAB, DP1 SE Nr. 935, Bl. 3-6. Vgl. dazu Amos, Justizverwaltung, S. 40 f. 
2. Personalien, 3. Allgemeine Verwaltung, 4. Haushaltssachen - sollten für die Justizabteilungen ausreichend $\operatorname{sein}^{36}$.

Zwar ist eine direkte Antwort aus Karlshorst nicht überliefert, jedoch mußte die Äußerung Karassjows, derzufolge auch er „die verschiedenartige Organisation der Justizabteilungen in den einzelnen Ländern und Provinzen für nicht zulässig" hielt, und seine Weisung an die DJV, einen Musterstellenplan für die Justizabteilungen zu erstellen, dort als Zustimmung interpretiert werden ${ }^{37}$. Daraufhin übersandte die Zentralverwaltung am 9. und 11. April einen Entwurf für den Aufbau der Justizabteilung an die Präsidenten der Länder und Provinzen mit der Bitte um Stellungnahme ${ }^{38}$. Die Antworten aus Sachsen und Brandenburg waren durchweg ablehnend, während der Leiter der mecklenburgischen Justizabteilung, Wilhelm Heinrich, keine Einwände gegen den Gliederungsentwurf hatte. Er stimmte freilich mit Vizepräsident Uhle aus Dresden und Präsident Steinhoff aus Potsdam darin überein, daß die Verwaltungsgeschäfte, die längst von den Justizverwaltungen wahrgenommen wurden, nicht wieder auf die Oberlandesgerichtspräsidenten und Generalstaatsanwälte übertragen werden sollten ${ }^{39}$. Ungeachtet dieser Einwände setzte die DJV ihre Aktivitäten zur Vereinheitlichung der Justizabteilungen nach ihren Vorstellungen in Konsultation mit der Finanzabteilung und der Rechtsabteilung der SMAD fort ${ }^{40}$, bis diese am 27. Juni die von ihr bestätigten Stellenpläne für die einzelnen Justizabteilungen einem Dolmetscher der Zentralverwaltung übergab41. Am 5. Juli schließlich ermächtigte Oberstleutnant Lyssjak die DJV, die Stellenpläne den Justizabteilungen der Länder und Provinzen „Zwecks Vorbereitung der Organisationsarbeiten“ zu übermitteln. „Endgültig“ würden die Finanzabteilungen der örtlichen Militärverwaltungen die Präsidenten der Länder und Provinzen von der Neuregelung in Kenntnis setzen ${ }^{42}$.

Die SMAD-Rechtsabteilung hatte am 24. April auch Karl Polak von der SEDJustizabteilung in dieser Frage konsultiert. Der zog tags darauf Melsheimer und Benjamin zu Rate, und gemeinsam erarbeiteten sie eine Struktur, die - wie der DJV-Vorschlag - die vier Abteilungen Gesetzgebung und Justiziariat (I), Personalien (II), Strafvollzug und Gnadensachen (III) sowie Haushalt (IV) enthielt. Ihr Entwurf wies freilich einen entscheidenden Unterschied zu dem der DJV auf: Die gesamte Justizverwaltung sollte der Justizabteilung übertragen und den Oberlandesgerichtspräsidenten und Generalstaatsanwälten entzogen werden, um auf diese

36 Chef der DJV an Chef der SMAD-Rechtsabteilung, 8. 3. 1946, BAB, DP1 SE Nr. 935, Bl. 7-9, teilweise zit. bei Lorenz, Zentralverwaltung, S. 150; vgl. auch Amos, Justizverwaltung, S. $41 \mathrm{f}$.

37 Vermerk über die Besprechung Schiffers und Karassjows am 18.3. 1946, BAB, DP1 VA Nr. 11, Bl. 28; vgl. auch Nachtrag zu diesem Aktenvermerk, 22. 3. 1946, ebenda, Bl. 32.

38 Die Schreiben an die Landes- und Provinzialpräsidenten in: BAB, DP1 SE Nr. 935, Bl. $91 \mathrm{ff}$.

39 Präsident Mecklenburg-Vorpommern/Abt. Justiz an DJV, 17. 4. 1946, Landesverwaltung Sachsen/ Abt. Justiz an DJV, 20. 4. 1946, Präsident der Provinzialverwaltung Mark Brandenburg an Chef der DJV, 20. 4. 1946, ebenda, Bl. 100, 34-37, 97-98. Die Antworten aus der Provinz Sachsen und Thüringen lagen nicht vor. Lorenz, Zentralverwaltung, S. $150 \mathrm{f}$., behauptet irrtümlicherweise, daß alle Justizverwaltungen den Vorschlag der DJV abgelehnt hätten.

40 Rosenthal-Pelldram an Vössing, 4. 5. 1946, BAB, DP1 SE Nr. 935, Bl. 18, über eine Besprechung mit der SMAD-Finanzabteilung; Vermerk über eine Besprechung am 3.6. 1946 mit Nikolajew, ebenda, Bl. $13 \mathrm{f}$.

41 Aktenvermerk v. Stackelberg, 28. 6. 1946, ebenda, Bl. 24; die Struktur- und Stellenpläne für Sachsen, Brandenburg und Mecklenburg ebenda, BI. 45, 89, 113.

42 Vermerk Rosenthal-Pelldram, 5. 7. 1946, ebenda, Bl. 22. 
Weise den Ländern und Provinzen entgegenzukommen und eine „rein politische Instanz" mit den Verwaltungsaufgaben zu betrauen, „da sie eine bessere Kaderauswahl und Kaderkontrolle sicherstellt, als diese durch die Oberlandesgerichtspräsidenten durchgeführt werden könnte [sic]“43. Da die SED langfristig alles andere als einen föderalistischen Staatsaufbau anstrebte, hatte die vorgeschlagene Übertragung der Verwaltungsangelegenheiten auf die Landesjustizverwaltungen einen rein taktischen Hintergrund: Während angesichts der Dominanz bürgerlicher Juristen an der Spitze der Oberlandesgerichte und Generalstaatsanwaltschaften kaum zu erwarten war, daß Kommunisten in diese Stellungen gelangen würden, besaß die SED auf die Dauer gute Chancen, die Personalabteilungen der Landes- und Provinzialjustizabteilungen zu besetzen. Der SMAD-Rechtsabteilung lag daher neben dem Vorschlag der DJV seit Ende April auch ein Entwurf der SED vor. Möglicherweise bildete dies den Hintergrund dafür, daß Nikolajew am 3. Juni Rosenthal-Pelldram beauftragte, „die Stellung der Justizabteilungen noch einmal unter möglichster Abgrenzung ihrer Zuständigkeiten darzustellen" und dabei auch das Verhältnis des Oberlandesgerichtspräsidenten und des Generalstaatsanwalts zur Justizabteilung sowie zur DJV zu erläutern ${ }^{44}$. Die Zusammenarbeit zwischen der SMAD-Rechtsabteilung und der DJV in dieser Frage verlief allem Anschein nach bis in den Juli hinein reibungslos; die Frage der Kompetenzabgrenzung zwischen Justizabteilung auf der einen und Oberlandesgericht und Generalstaatsanwaltschaft auf der anderen Seite wurde jedoch nicht mehr angesprochen. Im Juni 1946 hatte sich SMAD-intern unter dem Einfluß der SED ein Richtungswechsel durchgesetzt. Denn damals erhielt die Rechtsabteilung die $\mathrm{Zu}$ stimmung des Obersten Chefs der SMAD, Sokolowski, die Ernennung der Landgerichtspräsidenten und Generalstaatsanwälte den Landesjustizabteilungen zu übertragen ${ }^{45}$.

Daher endete die Diskussion der Frage auf einer Konferenz mit Vertretern der Justizabteilungen der Landes- und Provinzialregierungen ${ }^{46}$ am 16. August 1946 mit einer Niederlage der DJV. Einleitend stellte Rosenthal-Pelldram fest, daß nunmehr auch Thüringen ein „Landesamt Justiz“ erhalten habe, so daß „die Frage der Vereinheitlichung der Justizabteilungen der Länder und Provinzen in ein akutes Stadium getreten" sei. Daraufhin legte er nochmals deren geplante Gliederung und die Notwendigkeit der Aufteilung der Verwaltungsgeschäfte zwischen Justizabteilung und Oberlandesgericht dar, wobei er konzessionsbereit einräumte, daß „das Schwergewicht der Verwaltung bei den Justizabteilungen“ liege. Freilich erachtete er es für sinnvoll, Verwaltungsbefugnisse bei den Oberlandesgerichten zu belassen, da diese die Justizverwaltungen entlasten und fachkundig bei der Ernennung von Richtern sowie beim Einsatz von Referendaren mitwirken könnten.

43 Polak an Ulbricht, 26. 4. 1946, sowie der beigefügte Vorschlag mit gleichem Datum, SAPMO, NY 4182/1119, Bl. 37-39. Vgl. dazu Amos, Justizverwaltung, S. 42 f.

44 Vermerk über eine Unterredung mit Nikolajew am 3. 6. 1946, o.V., BAB, DP1 SE Nr. 935, Bl. 13 f. Da Rosenthal-Pelldram alle Verhandlungen über diese Frage führte und die in seiner Abteilung erarbeiteten Organisationspläne bei dieser Gelegenheit erörtert wurden, kommt als Verfasser jedoch nur er in Frage.

45 Vgl. Nikitin, Sowjetische Militäradministration und die Justiz (Manuskript), S. 2 f.

46 Dabei handelte es sich um die vierte sog. „Länder-“ oder „Gesetzgebungskonferenz": vgl. dazu den nächsten Abschnitt. 
Schließlich, und das schien ihm das wichtigste zu sein, wollte er den Oberlandesgerichtspräsidenten nicht auf seine Funktion als Vorsitzenden eines Rechtsmittelgerichts beschränken; dieser müsse vielmehr „in die Lage versetzt werden, belehrend und helfend auf die Richter und Beisitzer einwirken zu können“, wozu er freilich "gewisser Verwaltungsbefugnisse“ bedürfe - „des Rechts der Revision, des Einblicks in die Statistik, in die Geschäfte der Amts- und Landgerichte“. Alle Landes- und Provinzialvertreter lehnten erwartungsgemäß die Aufteilung der Verwaltungskompetenzen ab; nur Helmut Külz aus Thüringen berichtete, daß dort ein Teil der Personalangelegenheiten an den Oberlandesgerichtspräsidenten delegiert würden.

Während die SMAD-Rechtsabteilung in der Vergangenheit die DJV stets gegen die Länder unterstützt hatte, nahm sie nun eine Wendung um $180 \mathrm{Grad}$ vor. Denn Nikolajew verkündete, „daß die SMA derselben Meinung [sei], wie die Vertreter der Länder und Provinzen“. Die Oberlandesgerichtspräsidenten sollten von ihren Verwaltungsaufgaben entlastet werden, damit sie sich ganz auf ihre richterliche Tätigkeit konzentrieren könnten. Denn die Rechtsabteilung habe bei Revisionen des öfteren festgestellt, daß die Gerichte Fehlurteile ausgesprochen hätten, die in der zweiten Instanz nicht berichtigt worden seien. Auch das Recht der Richterernennung sprach er allein den Justizabteilungen zu und betonte, daß dies nicht $\mathrm{zu}$ den Kompetenzen der Landesbehörden, der DJV oder der Oberlandesgerichte gehöre. Schließlich sollte seiner Meinung nach die Landesjustizverwaltung, die „im Zentrum der Demokratisierungsarbeit" stehe, auch auf die Praxis der Gerichte einwirken, während das Oberlandesgericht "die Praxis zu verwirklichen" habe" Damit wurde die Position der Justizabteilungen nicht nur gegenüber den Oberlandesgerichten, sondern auch gegenüber der DJV erheblich gestärkt. Der Gesinnungswandel auf seiten der SMAD-Rechtsabteilung ist zum Teil auf die von ihr festgestellten Mängel in der Rechtsprechung der Gerichte zurückzuführen, für die die DJV bereits am 31. Juli gerügt worden war ${ }^{48}$. Außerdem hatte sich die SMAD in dieser Frage an dem Ratschlag der SED orientiert, ohne ihre Meinungsänderung vorher der DJV mitzuteilen.

Das Ergebnis der Besprechung schlug sich jedenfalls in geplanten Modifizierungen des DJV-Statuts nieder, die am 19. September und 22. Oktober von Nikolajew und Jakupow den DJV-Vertretern übermittelt wurden. Eine Änderung betraf den Abschnitt über die Dienstaufsicht über den Personalbestand, die die DJV nun nicht mehr durch die Oberlandesgerichtspräsidenten und Generalstaatsanwälte, sondern „unmittelbar oder durch die Justizabteilungen der Länder und Provinzen" ausüben sollte. Überdies wurde ihr die Ernennung der Landgerichtspräsidenten und Oberstaatsanwälte bei den Landgerichten entzogen und den Präsidenten der Provinzen und Länder übertragen ${ }^{49}$. Eine weitere Auswirkung der

47 Stenographisches Protokoll der Konferenz vom 16. 8. 1946, BAB, DP1 VA Nr. 6957; für die Zitate aus den Außerungen Rosenthal-Pelldrams siehe Bl. 22, 26, 30f.; für Nikolajews Ausführungen siehe Bl. 38-40.

48 Aktenvermerk über den Besuch Schiffers in Karlshorst am 31.7. 1946, BAB, DP1 VA Nr. 11, Bl. $62 \mathrm{f}$.

49 Aktenvermerk über die Besprechung Schiffers mit Nikolajew am 19.9. 1946, BAB, DP1 VA Nr. 11, Bl. 68. Weitere Änderungen, die nicht auf die Konferenz vom 16.8. zurückzuführen waren, betrafen die Aufzählung der Tätigkeitsfelder der Justizbehörden, die um die Gefangenenanstalten 
Konferenz vom August 1946 war, daß die Vereinheitlichung der Justizabteilungen zunächst nicht weiterverfolgt wurde. Denn mit der Entscheidung, den Oberlandesgerichtspräsidenten keinerlei Verwaltungsaufgaben zuzugestehen, waren auch die von der DJV ausgearbeiteten und von der SMAD-Rechtsabteilung bestätigten Stellenpläne hinfällig geworden. Schließlich waren auch die Tage der Justizabteilungen spätestens seit der offiziellen Ankündigung der Landtagswahlen am 11. September $1946^{50}$ gezählt: Denn es war abzusehen, daß nach den Wahlen in den einzelnen Ländern und Provinzen Justizministerien an ihre Stelle treten würden.

\section{Die Länderkonferenzen der Jahre 1946/47}

Mit dem Scheitern der Versuche einer zentralen Lenkung der Justizabteilungen von Berlin aus rückte für die DJV, sofern sie nicht ausdrücklich von der SMADRechtsabteilung mit der Durchführung eines Befehls betraut war, die Koordination der Justizarbeit in den Ländern und Provinzen in den Mittelpunkt ihrer Tätigkeit. Zunächst dachte Schiffer freilich nicht an Beratungen mit den Leitern der Justizabteilungen, sondern an eine Zusammenkunft der Oberlandesgerichtspräsidenten unter seinem Vorsitz. Dabei sollte es um Fragen der Justizverwaltung, um Gesetzgebung und um Rechtsanwendung gehen ${ }^{51}$. Die SMAD-Rechtsabteilung war mit dem Vorschlag einverstanden und ließ Schiffer am 8. Januar übermitteln, die Konferenz solle möglichst bald stattfinden ${ }^{52}$. Es blieb jedoch nicht bei der Beschränkung auf die Oberlandesgerichtspräsidenten, was Schiffers Vorstellungen wohl am meisten entsprochen hätte. Denn am 8. Februar, als das Thema wieder von Schiffer, diesmal in Gegenwart von Karassjow, angesprochen wurde, waren auch die Leiter der Justizabteilungen als Teilnehmer vorgesehen ${ }^{53}$. Die Konferenz fand unter Teilnahme Karassjows am 15./16. Februar 1946 statt $^{54}$. Im Anschluß daran teilte Schiffer Karlshorst mit, daß die Leiter der Landes- und Provinzialjustizverwaltungen auf der Konferenz angeregt hätten, „Vertreter der Justizabteilungen zur mündlichen Aussprache mit der Deutschen Justizverwaltung über notwendig gewordene Gesetzgebungsmaßnahmen in regelmäßigen Zwischenräumen nach Berlin einzuladen" 55 .

ergänzt wurden, Ziffer 3 des 2 . Abschnitts (ursprünglich: Kontrolle über der Tätigkeit der Gerichte usw., jetzt: Leitung der Tätigkeit der Gerichte usw.) und Ziffer 5 des 2. Abschnitts (hier wurde der DJV die Kompetenz zur Zulassung aller Rechtsanwälte und Notare entzogen und auf die Zulassung der Rechtsanwälte bei den Oberlandesgerichten beschränkt). Aktenvermerk vom 22. 10. 1946, ebenda, Bl. 77.

50 Vgl. Creuzberger, Sowjetische Besatzungsmacht, S. 44.

51 Schiffer an Chef der SMAD-Rechtsabteilung, 20. 9. 1945, BAB, DP1 VA Nr. 2, Bl. 106. Der Brief wurde nicht abgeschickt.

52 Vermerk einer Besprechung mit Nikolajew am 8. 1. 1946, BAB, DP1 VA Nr. 11, Bl. 4.

53 Aktenvermerk über die Besprechung zwischen Schiffer und Karassjow am 8. 2. 1946, BAB, DP1 VA Nr. 2, Bl. 187. Die Hintergründe für die Erweiterung des Teilnehmerkreises gehen aus den Akten nicht hervor.

54 Ein Protokoll ist nicht überliefert; die Teilnahme von Karassjow geht aus dem Vermerk über die Besprechung Schiffers mit Karassjow am 18.3. 1946, BAB, DP1 VA Nr. 11, Bl. 26, hervor.

55 Chef der DJV an SMAD-Rechtsabteilung, 23. 2. 1946, BAB, DP1 VA Nr. 6957, Bl. 4. 
Die damit inaugurierten „Länderkonferenzen“ verfolgten somit sehr viel begrenztere Ziele als Schiffer im November 1945. Gleichwohl lagen sie auch in seinem Interesse, bot sich ihm doch hier eine Gelegenheit, den im Statut der DJV niedergelegten Anspruch auf Koordinierung der Gesetzgebung zu verwirklichen. Wie sehr die DJV auf die Länderkonferenzen angewiesen sein sollte, war freilich zu Beginn des Jahres 1946 noch nicht abzusehen. Für Melsheimer bestanden damals die Aufgaben der Abteilung V mit Blick auf die Ländergesetzgebung darin, „die von den Ländern und Provinzen bereits erlassenen Gesetze und Verordnungen zu koordinieren“ und "die schwebenden und zukünftigen Gesetzgebungsarbeiten in den Ländern und Provinzen gleichzurichten “. Während die erste Aufgabe Korrekturen an bereits erlassenen Rechtsvorschriften implizierte, war die Voraussetzung einer "Gleichrichtung" der Ländergesetzgebung eine enge und frühzeitige Einbeziehung der DJV in die entsprechenden Arbeiten auf Landesebene $^{56}$. Dies entsprach freilich nicht der damals üblichen Praxis. Gegenüber Karassjow gestand Schiffer am 9. Februar, daß er über die Rechtsakte aus den Ländern und Provinzen bislang nur durch die Presse erfahren habe. Unter Berufung auf das Statut werde er jedoch die Provinzial- und Länderregierungen veranlassen, alle Gesetze und Verfügungen vor ihrer Verkündigung bei der DJV einzureichen $^{57}$. Obwohl Karassjow zustimmte, erfüllte sich die Hoffnung Schiffers, mit Unterstützung der SMAD-Rechtsabteilung diesen Passus des Statuts durchzusetzen, nicht. Da die Länder sich in ihrer Gesetzgebungsarbeit grundsätzlich nicht durch die DJV stören ließen, entwickelte auch Schiffer ein reges Interesse an den Länderkonferenzen, die er am liebsten alle vier Wochen abgehalten hätte.

Dagegen wandte sich jedoch der Chef der SMAD-Rechtsabteilung, der anordnete, daß die Konferenzen nur "nach Bedarf“ stattfinden und sorgfältig vorbereitet werden sollten ${ }^{58}$. Zudem bestand Karlshorst ab Juni 1946 darauf, daß für die Länderkonferenzen eine Genehmigung der SMAD-Rechtsabteilung einzuholen sei; ebenfalls sollten die zur Beratung anstehenden Entwürfe übersandt werden ${ }^{59}$. Ab November 1946 kam eine die DJV irritierende Weisung hinzu, den Ländern und Provinzen die Protokolle über die Tagungen nicht mehr zuzusenden. Als Begründung führte Nikolajew an, daß in der Vergangenheit aufgrund dieser Protokolle "voreilig Verordnungen erlassen worden seien, die den Wünschen der Rechtsabteilung nicht entsprochen hätten" 60 . Damit wollte sich der zuständige Vertreter der Gesetzgebungsabteilung in der DJV nicht abfinden und wies Melsheimer darauf hin, „daß hierdurch der praktische Erfolg der Länderkonferenzen stark herabgemindert werden würde und daß daher alles versucht werden müßte, Karlshorst zu einem Widerruf seiner Anordnung zu bewegen"61. Wenngleich die

56 Aufgaben der Abteilung V (Gesetzgebung), 30. 1. 1946, BAB, DP1 VA Nr. 1043, Bl. 36. Vgl. auch Melsheimer an Schiffer, 11. 2. 1946, ebenda, Bl. 30.

57 Aktenvermerk über die Besprechung zwischen Schiffer und Karassjow am 8. 2. 1946, BAB, DP1 VA Nr. 2, Bl. $185 \mathrm{f}$.

58 Vermerk über die Besprechung Schiffers mit Karassjow am 18.3. 1946, BAB, DP1 VA Nr. 11, Bl. 26; vgl. Amos, Justizverwaltung, S. 53.

59 Aktenvermerk über einen Anruf Lyssjaks, 5. 6. 1946, BAB, DP1 VA Nr. 839, Bl. 153; vgl. Amos, Justizverwaltung, S. 53.

60 Aktenvermerk über Rücksprache mit Nikolajew am 14.11. 1946, 19.11. 1946, BAB, DP1 VA Nr. 11, Bl. 83.

61 Vermerk Guski, 3. 12. 1946, BAB, DP1 VA Nr. 6957, Bl. 115. 
DJV dort zweimal in diesem Sinne vorstellig wurde62, erfolgte keine Reaktion. Am 4. Dezember 1946 verlangte Oberstleutnant Jakupow zudem, daß die Tagesordnungen der Länderkonferenzen zuerst von der SMAD-Rechtsabteilung genehmigt werden müßten, bevor man sie an die Länder und Provinzen absende ${ }^{63}$. Schließlich wünschte er im Januar 1947 auch noch über die Stellungnahmen der DJV zu den einzelnen Beratungsthemen im voraus informiert zu werden, um diese „abzusegnen“64. All diese Anweisungen verdeutlichen, wie eng die Rechtsabteilung den Rahmen der Länderkonferenzen absteckte. Ihr kam es anscheinend nicht so sehr darauf an, daß hier effektiv gearbeitet wurde, sondern daß sie zu keiner Zeit die Kontrolle über das "Gesetzgebungsverfahren“ verlor. Weitere Einwirkungsmöglichkeiten ergaben sich für sie daraus, daß sie fast immer zwei oder drei Vertreter zu den Zusammenkünften entsandte ${ }^{65}$. Hier bot sich der SMADRechtsabteilung somit ein wichtiges Forum zur Übermittlung und Auslegung von Anweisungen, da sie bei diesen Gelegenheiten nicht nur die DJV, sondern auch die Ländervertreter erreichte.

Auf den insgesamt neun Konferenzen dieser Art, die in den Jahren 1946 und 1947 stattfanden 66 , wurden, teils auf Antrag der Länder, teils auf Antrag der DJV, die unterschiedlichsten Materien behandelt, die nach Meinung der Akteure einer einheitlichen Regelung bedurften. $\mathrm{Zu}$ einem großen Teil ging es dabei um den juristischen Umgang mit Recht und Justiz der NS-Zeit: Welche Urteile waren aufzuheben, welche Rechtsvorschriften zu „entnazifizieren“, welche Normen, etwa im Strafverfahrensrecht, konnten noch angewandt werden? Ebenfalls in diesem Zusammenhang standen die Probleme, die sich aus dem Übergang von der Rechtsordnung des Dritten Reiches in die der Nachkriegszeit ergaben: Welches Gericht war unter den neuen Bedingungen für welche Gerichtsverfahren zuständig? Wer sollte das Gnadenrecht ausüben? Zu diesem Problemfeld zählen auch Sanktionen gegenüber ehemaligen Nationalsozialisten sowie die Wiedergutmachung von nationalsozialistischem Unrecht. Darüber hinaus ging es um die Einführung und Auslegung neuer Rechtsnormen. Dies betraf zum einen das $\mathrm{Ge}$ richtsverfassungsrecht: Behandelt wurden dabei nicht nur die Rechtsstellung der Volksrichter, sondern auch die Entlastung der Gerichte und Staatsanwaltschaften, die Besetzung der Gerichte und die Berufung von Schöffen ins Geschworenenamt. Zum anderen galt es, neue, von der sowjetischen Besatzungsmacht oder dem Alliierten Kontrollrat erlassene Rechtsnormen zu erläutern: In diesen Kontext gehören sowohl die SMAD-Befehle Nr. 160 vom Dezember 1945 und Nr. 201 vom August 1947 als auch die Kontrollratsgesetze Nr. 45 vom Februar und Nr. 50 vom März 194767. Welche Rolle diese Tagungen im Rahmen der "Gesetzgebung“

62 Chef der DJV an SMAD-Rechtsabteilung, 4. 12. 1946, 16. 6. 1947, ebenda, Bl. 117, 164.

63 Vermerk über Besprechung mit Jakupow am 4. 12. 1946, ebenda, Bl. 174.

64 Äußerung Winkelmanns auf der Dienstbesprechung der DJV vom 22. 3. 1947: siehe Vermerk über die Besprechung, 23. 1. 1947, BAB, DP1 VA Nr. 7354.

65 Nur zur Konferenz vom 3. 5. 1946 entsandte sie keine Vertreter: siehe das Konferenzprotokoll, $\mathrm{BAB}, \mathrm{DP} 1 \mathrm{VA}$ Nr. 22, Bl. 1. An der Konferenz vom 14./15. 11. 1947 nahmen sogar fünf SMADOffiziere teil: siehe das Konferenzprotokoll, BAB, DP1 VA Nr. 6332.

66 Auffällig ist, daß 1946 sechs, 1947 aber nur drei Konferenzen stattfanden: für die Daten siehe Amos, Justizverwaltung, S. 52.

67 Darüber hinaus ging es auch um zahlreiche andere, nicht zu diesen Problemkreisen zählenden Normativakte. Die Tagesordnungen der Länderkonferenzen in: BAB, DP1 VA Nr. 780, Bl. 18-30. 
in der SBZ spielten, läßt sich aufgrund der unterschiedlichen Materien und der jeweils unterschiedlichen Entwicklungen letztlich nur im Einzelfall bestimmen ${ }^{68}$. Die Protokolle erwecken den Eindruck, daß sie eher dem Gedankenaustausch als der Entscheidungsfindung dienten. Nur wenn die sowjetischen Vertreter ihre Meinungen kundtaten, hatte dies in der Regel entsprechende Konsequenzen. Da die Autorität der DJV nur schwach ausgeprägt war, war sie kaum in der Lage, die Konferenzen zur Koordinierung der Gesetzgebung zu nutzen.

Anhand des Gesetzes zur Bestrafung von Gerüchtemachern läßt sich illustrieren, wie gering die Chancen der DJV waren, bei „Gesetzgebungsverfahren“ koordinierend zu wirken, selbst wenn die Materien auf den Länderkonferenzen behandelt wurden. Bereits Marschall Schukow hatte auf der Konferenz vom 13./ 14. November 1945 gefordert: „Sie müssen sich vor allen Dingen gegen die Gerüchtemacherei zur Wehr setzen. Die Quellen, aus denen die Gerüchte kommen, sind uns und auch Ihnen bekannt. Sie sind nur geeignet, das Mißtrauen und die Unruhen zu verstärken. Schaffen Sie organisatorische Maßnahmen zur Bekämpfung der Gerüchtemacherei." 69 Daraufhin wurde die thüringische Landesverwaltung aktiv, deren Präsident am 20. Dezember ein „Gesetz gegen die Gerüchtemacherei“ erließ70. Am 22. Februar 1946 überreichte zudem der Leiter der brandenburgischen Justizabteilung, Walther Hoeniger, in der DJV den „Entwurf eines Gesetzes zur Sicherung des Aufbauwillens der Bevölkerung“, das ebenfalls eine Bestrafung der Gerüchtemacher vorsah ${ }^{71}$. Melsheimer bat Hoeniger, mit einer Verabschiedung des Gesetzes noch zu warten, da die DJV einen ähnlichen Verordnungsentwurf ausgearbeitet habe, der auf der Länderkonferenz am 11. März behandelt werden solle ${ }^{72}$. Die Diskussion über die von Melsheimer dort vorgestellte Verordnung bezog sich zum einen auf die Art der Bestrafung und zum anderen darauf, ob nur vorsätzliche oder auch fahrlässige Gerüchtemacherei zu bestrafen sei. Melsheimer wie auch Oberstleutnant Lyssjak lobten in diesem $\mathrm{Zu}$ sammenhang das Thüringer Gesetz; Lyssjak fügte jedoch hinzu, daß die SMADRechtsabteilung der Meinung sei, „daß dies ein Gesetz [sei], welches für die ganze Zone erlassen werden müßte, und zwar von der SMA selbst"73. Es bestanden demnach gute Voraussetzungen für die DJV, trotz des thüringischen Vorpreschens noch eine einheitliche Regelung dieses Problems zu erreichen. Nach Rücksprache

Bis auf die Konferenz vom 4./5. 7. 1947 liegt für alle Konferenzen im Bestand DP1 VA ein Protokoll vor.

68 Daher wird hier keine eingehende Geschichte der Länderkonferenzen geboten. Sie werden aber in der Darstellung immer dann erwähnt, wo es, wie etwa im Zusammenhang mit der Rechtsprechung zu Befehl Nr. 160, inhaltlich notwendig ist.

69 Niederschrift des Präsidenten des Landes Mecklenburg-Vorpommern, Wilhelm Höcker, über eine Tagung der Präsidenten der Länder und der Deutschen Zentralverwaltungen in der Sowjetischen Besatzungszone Deutschlands, 13./14.11. 1945, in: Um ein antifaschistisch-demokratisches Deutschland, S. $203 \mathrm{f}$.

70 Regierungsblatt für Thüringen 1946, Teil 1, S. $7 f$.

71 Provinzialverwaltung Mark Brandenburg, Abt. Justiz, an Chef der DJV, 21. 2. 1946, BAB, DP1 VA Nr. 120, Bl. 1. Hoeniger berief sich auf den stellvertretenden Leiter der SMA Brandenburg, der bereits im Januar ein solches Gesetz gefordert habe. Auf dem Schreiben vermerkte Melsheimer, daß Hoeniger den Gesetzentwurf am 22.3. 1946 übergeben habe. Zu Hoeniger siehe Pohl, Justiz in Brandenburg (Manuskript).

72 Vermerk Melsheimers, 22. 3. 1946, BAB, DP1 VA Nr. 120, Bl. 1.

73 Protokoll der Länderkonferenz vom 11.3. 1946, BAB, DP1 VA Nr. 839, Bl. 207. 
mit Karassjow übersandte Schiffer diesem am 23. März einen entsprechenden Verordnungsentwurf, der sowohl die absichtliche als auch die leichtfertige Verbreitung von Gerüchten mit dem Ziel, „das Vertrauen zu der Wiederaufbauarbeit des deutschen Volkes zu erschüttern oder eine den Wiederaufbauwillen lähmende Beunruhigung in der Bevölkerung zu erregen“", unter Strafe stellte ${ }^{74}$.

Die verspätete Reaktion der Rechtsabteilung machte eine einheitliche Regelung unmöglich. Als Melsheimer auf der Landeskonferenz am 14./15. Juni mitteilte, $\mathrm{da} ß$ in dem von Oberstleutnant Lyssjak übergebenen „Entwurf eines Gesetzes über die Ergänzung der geltenden Strafgesetze" auch die von der DJV erarbeitete "Gerüchtemacherverordnung" enthalten sei, war in Brandenburg bereits eine eigene Verordnung in $\mathrm{Kraft}^{75}$, die im Strafmaß erheblich von dem DJV-Vorschlag abwich $^{76}$. In noch größere Schwierigkeiten geriet die DJV jedoch, als Lyssjak sie am 12. Juli informierte, daß die SMAD-Rechtsabteilung von dem Vorhaben völlig abrücke, da „es nicht mehr zeitgemäß sei, eine Verordnung gegen die Gerüchtemacherei zu erlassen, da eine derartige Verordnung als undemokratisch aufgefaßt werden könnte “77. Der DJV blieb nichts anderes übrig, als die Justizabteilungen darum zu bitten, von einer gegebenenfalls vorbereiteten Verordnung Abstand zu nehmen und, „soweit eine solche Verordnung bereits erlassen sei, zur Frage ihrer Aufhebung alsbald Stellung zu nehmen"78. Während Hoeniger daraufhin die Staatsanwaltschaften anwies, keine Anklagen aufgrund der brandenburgischen Verordnung zu erheben, und ihre Sistierung vorbereitete, lehnten das „Landesamt für Justiz" in Weimar sowie Generalstaatsanwalt Friedrich Kuschnitzky die Außerkraftsetzung des thüringischen Gesetzes ab. „Wenn wir auf Ihre und die Vorstellungen der Rechtsabteilung der SMA Karlshorst das Gesetz wieder aufheben würden," so begründete Helmut Külz am 8. Oktober die ablehnende Haltung Thüringens gegenüber der DJV, „würden wir damit eine übergeordnete Instanz über unserer Gesetzgebungsbefugnis gemäß Befehl 110/45 der SMAD anerkennen." "79 Solange keine förmliche Anordnung der SMAD in dieser Angelegenheit erfolgte, bestanden die Thüringer folglich auf ihrem Gesetzgebungsrecht. Daraufhin wurde in der DJV Mitte Januar entschieden, die SMAD-Rechtsabteilung nicht einzuschalten und angesichts der Unklarheit über die Gestaltung des Verhältnisses zu den nunmehr gebildeten Länderregierungen „die Sache einstweilen auf Eis zu legen" 80 .

74 Vermerk über die Besprechung Schiffers mit Karassjow am 18.3. 1946, BAB, DP1 VA Nr. 11, Bl. 26; Chef der DJV an SMAD-Rechtsabteilung, 23. 3. 1946, BAB, DP1 VA Nr. 839, Bl. 196; Verordnungsentwurf ebenda, Bl. 199.

75 Protokoll über die Länderkonferenz vom 14./15. 6. 1946, BAB, DP1 VA Nr. 22,Bl. $26 \mathrm{f}$.

76 Die brandenburgische Verordnung zur Sicherung des Aufbauwillens der Bevölkerung vom 6. 6. 1946 in: BAB, DP1 VA Nr. 120, Bl. 6.

77 Aktenvermerk über einen Anruf Lyssjaks, 12. 7. 1946, ebenda, Bl. 8. Warum die SMAD-Rechtsabteilung ihre Auffassung änderte, ließ sich nicht feststellen.

78 Chef der DJV an Landes- und Provinzialverwaltungen/Abt. Justiz, 23. 7. 1946, ebenda, Bl. 9.

79 Vgl. thüringisches Landesamt für Justiz an DJV, 11. 9. 1946 (mit Stellungnahme Kuschnitzkys vom 15. 8. 1946); DJV an Landesamt für Justiz, 30. 9. 1946; Landesamt für Justiz an DJV, 8. 10. 1946, ebenda, Bl. 15-18. Zu dem Vorgang sehr knapp Lorenz, Zentralverwaltung, S. $147 \mathrm{f}$.

80 Vermerk vom 11.1.1947 aus der Abteilung V der DJV, BAB, DP1 VA Nr. 120, Bl. 23; auf dem Vermerk befinden sich die zustimmenden Bemerkungen Winkelmanns vom 14.1. 1947 (daraus auch das Zitat) und die Entscheidung Melsheimers vom 15.1. 1947. 
Die DJV war in der Beziehungskette zwischen SMAD-Rechtsabteilung und Landesjustizverwaltungen das schwächste Glied. Die Landes- und Provinzialverwaltungen sahen nach Erlaß von Befehl Nr. 110 keine Veranlassung, sich dem Lenkungsanspruch der DJV zu unterwerfen. Diese konnte daher die Gesetzgebung nur dann koordinieren, wenn die SMAD-Rechtsabteilung sie konsequent und vorbehaltlos unterstützte. Da Karlshorst jedoch, wie der dargestellte Fall zeigt, den Prozeß verzögern und zudem widersprüchliche Weisungen erteilen konnte, wurde die Stellung der DJV gegenüber den Ländern weiter geschwächt. Eine Durchsetzung der Ansprüche des Statuts erschien um die Jahreswende 1946/ 47 so gut wie unmöglich.

\section{Die Zuspitzung des Konflikts zwischen Zentrale und Ländern im Jahre 1947}

Aufgrund der Wahlen vom Oktober 1946 traten in den Ländern und Provinzen mit den Landtagen und Landesregierungen demokratisch legitimierte Organe an die Stelle der von der Besatzungsmacht ernannten Selbstverwaltungen. Indem die SMAD die Präsidenten der Länder und Provinzen mit Befehl Nr. 332 vom 27. November 1946 aufforderte, alle ihnen verliehenen Vollmachten den Parlamenten und zu bildenden Regierungen zu übergeben ${ }^{81}$, sanktionierte sie zwar diese Entwicklung, verdeutlichte jedoch gleichzeitig, daß sie sich auch weiterhin die letzte Entscheidung über die Verteilung der Machtbefugnisse in ihrer Zone vorbehielt. Hinzu kam, daß jedes Land und jede Provinz sich "auffallend schnell“ im Zeitraum zwischen dem 20. Dezember 1946 (Thüringen) und dem 28. Februar 1947 (Sachsen) eine eigene Verfassung gab, in der die Kompetenzen der eigenen Organe ohne Bezug auf die bereits existierenden Zentralinstanzen festgelegt wurden $^{82}$. Dies schwächte die Position der Zentralverwaltungen, die nur besatzungsrechtlich, nicht aber demokratisch legitimiert und deren Kompetenzen nicht in einer Verfassung niedergelegt waren. Unter diesen Bedingungen spitzte sich 1947 der Konflikt zwischen den äußerst selbstbewußt auftretenden Ländervertretern ${ }^{83}$ und den Zentralverwaltungen $\mathbf{z u}^{84}$.

Mit Befehl Nr. 332 und der Bestätigung der Landesverfassungen hatte die SMAD zwar ihr Einverständnis mit der föderalen Entwicklung in ihrer Zone signalisiert; aufgrund übergeordneter deutschlandpolitischer Zielsetzungen und damit konfligierender Interessen der Militärverwaltung blieb die Haltung der sowjetischen Besatzungsmacht in den Auseinandersetzungen des Jahres 1947 jedoch höchst ambivalent. Einerseits hatte sich Stalin am 31. Januar 1947 angesichts der bevorstehenden Außenministerkonferenz in Moskau gegen die ab Mitte 1946

81 Befehl Nr. 332 in: Um ein antifaschistisch-demokratisches Deutschland, S. 347.

$\$ 2$ Vgl. Braas, Verfassungsgebung, S. 359; zum Entstehungsprozeß ausführlich ders., Entstehung.

83 Nach Auflösung des Staates Preußen mit Kontrollratsgesetz Nr. 46 vom 25. 2. 1947 (Amtsblatt des Kontrollrats, Nr. 14, 31.3. 1947, S. 262) wurden nach entsprechenden Landtagsbeschlüssen mit SMAD-Befehl Nr. 180 vom 21. 7. 1947 aus der Provinz Sachsen das Land Sachsen-Anhalt und aus der Provinz Mark Brandenburg das Land Brandenburg.

${ }_{84}$ Vgl. Mielke, Auflösung, S. 37; Foitzik, Einleitung, in: Inventar, S. 37. 
von Teilen der SMAD und der SED-Führung angestrebte Bildung eines deutschen Zentralorgans in der SBZ ausgesprochen. Andererseits sah die SMAD in dem sich nach den Landtagswahlen entfaltenden Föderalismus, der in russischen Quellen als „Separatismus“ bezeichnet wurde, eine Gefahr. Dabei störten die SMAD-Informationsverwaltung insbesondere die "weitgehenden Vollmachten und Kontrollrechte der Landtage" 85 . Die sowjetische Politik oszillierte folglich in diesem Jahr zwischen Föderalismus und Zentralismus, was vor allem bei den Konflikten zwischen der DJV und den Landesjustizministerien deutlich wird.

Bereits Ende 1946 erreichten widersprüchliche Signale der SMAD-Rechtsabteilung die DJV. Am 3. Dezember erteilten Jakupow und Nikolajew Hilde Benjamin die Weisung, „einen allgemeinen Entwurf für die Struktur der etwa in den Ländern und Provinzen zu errichtenden Justizministerien " auszuarbeiten ${ }^{86}$. Dieser umgehend ausgeführte ${ }^{87}$ - Auftrag schien darauf hinzudeuten, daß die SMADRechtsabteilung die DJV nun wieder als zentralisierende Instanz benötigte. Zudem sagte Karassjow Schiffer am 20. Dezember seine Unterstützung bei der Koordinierung der Gesetzgebung zu. Der DJV-Präsident konnte also hoffen, daß seine Aufforderungen an die Länder zur rechtzeitigen Übersendung von Gesetzes- und Verordnungsentwürfen nicht mehr ungehört verhallten ${ }^{88}$. Bei derselben Gelegenheit berichtete Schiffer, daß der zentrale Blockausschuß ihn gebeten habe, die Vereinbarkeit des Landesverfassungsentwurfs mit den erlassenen Rechtsvorschriften des Kontrollrats und der SMAD zu überprüfen ${ }^{89}$. Dabei habe er festgestellt, daß die Bestimmung, nach der auch die Oberlandesgerichte Laien zur Rechtsprechung hinzuziehen sollten ${ }^{90}$, nicht mit Kontrollratsgesetz Nr. 491 übereinstimme. Dieses legte fest, daß das GVG von 1877 in der Fassung von 1924 wieder Geltung haben solle: Eine Mitwirkung von Laien an der Rechtsprechung der Oberlandesgerichte war damit jedoch ausgeschlossen. Wichtiger war Schiffer freilich, daß der SED-Verfassungsentwurf mit seiner Bestimmung, den Oberlandesgerichtspräsidenten und den Generalstaatsanwalt vom Landtag wählen zu lassen, dem Statut der DJV widersprach, das ja deren Ernennung dem Chef der DJV vorbehielt. Karassjow sprach sich indes „entschieden für die Wahl der Oberlandesgerichtspräsidenten und Generalstaatsanwälte durch die Landtage aus, ebenso für die Hinzuziehung von Laienbeisitzern zu den Sitzungen der Oberlandesge-

85 Pieck-Notat über die Besprechung am 31.1. 1947 in: Badstübner/Loth, Pieck-Aufzeichnungen, S. $112 \mathrm{f}$. Daraus geht aber auch hervor, daß Stalin den Föderalismus ablehnte. Vgl. insgesamt dazu Foitzik, Einleitung, in: Inventar, S. 38, 50 (Zitat).

86 Vermerk Benjamins, 5. 12. 1946, BAB, DP1 VA Nr. 6348.

87 DJV an SMAD-Rechtsabteilung, 4. 12. 1946, mit beigefügtem Strukturplan, ebenda. Der Plan sah die Abteilungen Personal (I), Strafrecht (II), Zivil- und Öffentliches Recht (III) und eine allgemeine Abteilung (IV) vor. Diese Vorstellungen wurden jedoch nie in die Praxis umgesetzt, und die Justizministerien erhielten eine von Land zu Land stark differierende Struktur: vgl. Anders, Demokratisierung, S. $97 \mathrm{f}$.

88 Aktenvermerk über die Besprechung Schiffers mit Karassjow am 20.12. 1946, BAB, DP1 VA Nr. 11, Bl. $90 \mathrm{f}$.

89 Vgl. Protokoll der Sitzung des Blockausschusses vom 17. 12. 1946, in: Suckut, Blockpolitik, S. 180.

90 Diese Bestimmung findet sich nur in dem damals diskutierten 2. Verfassungsentwurf der SED, Art. 67, in: Braas, Entstehung, S. 444.

91 Im Protokoll steht irrtümlich „Kontrollratsdirektive Nr. 4“; Aussagen zum Gerichtsverfassungsgesetz enthielt jedoch nur Kontrollratsgesetz $\mathrm{Nr} .4$ vom 30. 10. 1945, in: Amtsblatt des Kontrollrats, Nr. 2, 30. 11. 1945, S. 8 f. 


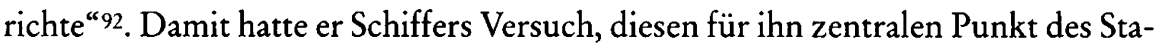
tuts durchzusetzen, eine Absage erteilt, so daß keineswegs klar war, ob die SMAD-Rechtsabteilung die DJV in ihren Zentralisierungsbemühungen weiterhin unterstützen würde.

In der Frage der Richterernennung kam es ebenfalls zu einem Konflikt zwischen der DJV und Thüringen im Januar 1947. In einer Unterredung am 27. Dezember 1946 hatten Justizminister Külz und Schiffer festgestellt, daß die Bestimmung des Statuts im Hinblick auf die Ernennung der Präsidenten und Mitglieder der Oberlandesgerichte sowie der Landgerichtspräsidenten mit der Thüringer Verfassung im Widerspruch stand. Denn Artikel 47 legte die Ernennung der Berufsrichter durch die Landesregierung fest; die Mitglieder des Oberlandesgerichts mußten vom Landtag bestätigt werden ${ }^{93}$. Da die SMA in Weimar die Verfassung am 6. Januar 1947 ohne Ergänzung von Artikel 47 um ein Mitwirkungsrecht der DJV billigte, folgerten Külz sowie der Rechts- und Verfassungsausschuß des Landtages daraus, daß das Statut der DJV, „das seine Rechtswirksamkeit aus der einem rechtsetzenden Befehle gleichgeachteten Bestätigung durch den Marschall Shukow herleitete, [...] durch die nunmehr der neuen Landesverfassung gegebene Bestätigung, die wiederum als rechtsetzender Befehl gelten muß, doch wohl als abgeändert abzusehen [sic, gemeint ist: anzusehen]" sei. Dennoch sagte der Justizminister zu, vor der Nominierung der Richter, deren Ernennung die DJV sich bisher vorbehalten habe, die DJV zu unterrichten und um ihre Stellungnahme zu bitten ${ }^{94}$. Eine Änderung des DJV-Statuts durch eine Landesverfassung konnte und wollte Schiffer nicht akzeptieren und legte am 28. Februar der SMADRechtsabteilung die Frage zur Entscheidung vor ${ }^{95}$.

Daß die DJV auf ihren im Statut niedergelegten Rechten weiterhin beharrte, belegt zudem eine Beschwerde Schiffers über die Ernennung mehrerer Oberlandesgerichtspräsidenten, Landgerichtspräsidenten und Staatsanwälte durch die Länderpräsidenten, bei denen die DJV entweder gar nicht benachrichtigt oder erst nach Überreichung der Ernennungsurkunde um ihr Einverständnis gebeten worden sei ${ }^{96}$. Im Hinblick auf die Gerichtsorganisation, bei der sich die DJV ein Mitwirkungsrecht vorbehielt, kam es zu Auseinandersetzungen in Sachsen-Anhalt. Eine seit 1946 vorgesehene und mit DJV-Erlaß angeordnete Neuregelung der dortigen Gerichtsorganisation war von der SMA in Halle zunächst verhindert worden. 1947 stellte sich der Landtag auf den Standpunkt, daß er die Sache gesetzlich regeln müsse. Die DJV stimmte diesem Verfahren zu, und man kam überein, in dem Gesetz zu erwähnen, daß die Neuregelung im Einvernehmen mit dem Chef der DJV erfolge. Dieser Zusatz wurde jedoch bei der endgültigen Annahme des

92 Aktenvermerk über die Besprechung Schiffers mit Karassjow am 20. Dezember 1946, BAB, DP1 VA Nr. 11, Bl. $91 \mathrm{f}$. Darin folgte Karassjow einem tags zuvor bei einer Besprechung im ZS der SED gemachten Vorschlag: vgl. Nikitin, Sowjetische Militäradministration und die Justiz (Manuskript), S. 3 .

93 Aktenvermerk über die Unterhaltung Schiffers mit Külz am 27. 12. 1946, BAB, DP1 SE Nr. 3559.

94 MdJ Thüringen an DJV, 20. 1. 1947, ebenda.

95 Chef der DJV an SMAD-Rechtsabteilung, 28. 2. 1947, ebenda.

96 DJV an SMAD-Rechtsabteilung, 14. 1. 1947, ebenda. 
Gesetzes gestrichen, so daß die Zentralverwaltung auch diesen Fall der SMADRechtsabteilung vorlegte ${ }^{97}$.

Während keine Antworten aus Karlshorst auf diese konkreten Anfragen überliefert sind, gab Oberstleutnant Jakupow auf der Länderkonferenz vom 11. April 1947, an der mit Erhard Hübener, Hermann Kastner und Ernst Stargardt erstmals drei für die Justiz zuständige Landesminister teilnahmen, eine das Verhältnis zwischen Zentrale und Ländern berührende Grundsatzerklärung ab. Unter ausdrücklicher Bezugnahme auf das Statut der Zentralverwaltung stellte er fest, „daß die DJV leitendes und kontrollierendes Organ ist bezüglich aller gerichtlichen und staatsanwaltschaftlichen Organisationen der Provinzen und Länder in der sowjetischen Besatzungszone“. Und er fuhr fort: „Sie stellt gleichzeitig die Verbindung her zwischen der SMAD und den J[ustiz]M[inisterien] der Länder und Provinzen. Die Anweisungen der DJV sind von allen J[ustiz]M[inisterien] der Länder und Provinzen zu erfüllen.“98 Diese Äußerung, die von Winkelmann als „,besonders vorteilhaft für die DJV “99 bezeichnet wurde, ist nicht nur in der DDR-Historiographie als entscheidender Schritt hin zur Zentralisierung des Justizwesens in der SBZ unter Führung der DJV angesehen worden ${ }^{100}$. Diese Auffassung ist freilich verfehlt. Denn Jakupow beschränkte sich in seinen konkreten Darlegungen zum DJV-Statut auf einige wenige Punkte: die Kontrolle und Aufsicht der Zentralverwaltung über die Tätigkeit der Gerichte, Staatsanwaltschaften, Notariate und Anwaltschaft, die Entnazifizierung des Justizpersonals und die Heranziehung neuer Kräfte zur Besetzung der Justizbehörden. Die Länderbehörden verpflichtete er lediglich dazu, „alle notwendigen Daten und Unterlagen auf Verlangen zu geben und rechtzeitig über die Kriminalität zu berichten"101. Damit verdeutlichte er, wo die SMAD-Rechtsabteilung ihre Schwerpunkte setze und die Länder daher den Anordnungen der DJV unbedingt Folge leisten mußten. Über die zwischen Zentralverwaltung und Landesministerien kontroversen Themen, insbesondere über das Ernennungsrecht hinsichtlich der leitenden Justizangestellen, schwieg er sich hingegen aus. Über das Verhältnis von Zentrale und Ländern wurde in der Rechtsabteilung zwar nachgedacht ${ }^{102}$, zu einem Ergebnis gelangte man 1947 in Karlshorst jedoch nicht.

Wie dringend die DJV jedoch Entscheidungen der SMAD benötigte, zeigen ihre Schwierigkeiten bei der Durchsetzung von Verordnungen gegenüber den auf ihr Gesetzgebungsrecht pochenden Ländern. Als erste bekundete die Provinzial-

97 MdJ Sachsen-Anhalt an DJV, 28. 6. 1947; DJV an SMAD-Rechtsabteilung, August 1947, BAB, DP1 VA Nr. 3, Bl. 76-78, 79. Bei dem Schreiben an die SMAD-Rechtsabteilung handelt es sich um das Konzept; wann es abgeschickt wurde, ist unklar.

98 Stenographisches Protokoll der Länderkonferenz vom 11.4. 1947, BAB, DP1 VA Nr. 6958, Bl. $31 \mathrm{f}$. In leicht abweichender Fassung teilweise zit. bei Benjamin u.a., Zur Geschichte der Rechtspflege 1945-1949, S. 186.

99 Vermerk über die Dienstbesprechung am 16. 5. 1947, BAB, DP1 VA Nr. 7354.

100 Benjamin u.a., Zur Geschichte der Rechtspflege 1945-1949, S. 186; Frank, Justizministerium, S. 85; Feth, Benjamin, S. 55; anders Lorenz, Zentralverwaltung, S. 148 f.

101 Stenographisches Protokoll der Länderkonferenz vom 11.4. 1947, BAB, DP1 VA Nr.6958, Bl. $31 \mathrm{f}$.

102 Siehe dazu die Aufforderungen an die DJV, den Reichsaufbau vor 1945 und in der Weimarer Republik insbesondere im Hinblick auf die Kompetenzen von Reich und Ländern darzustellen in: Vermerk Lange, 7. 3. 1947, und Vermerk v. Stackelberg, 14. 8. 1947, BAB, DP1 VA Nr. 6923. 
regierung von Sachsen-Anhalt im Januar 1947, nicht länger Verordnungen der Zentralverwaltungen im eigenen Verordnungsblatt abdrucken zu wollen. Denn nach Inkrafttreten der Provinzialverfassung liege das ausschließliche Gesetzgebungsrecht beim Landtag. Vor diesem Hintergrund erscheine es „zweifelhaft“, ob die keinem Parlament verantwortlichen Zentralverwaltungen „nur auf Grund einer allgemeinen Ermächtigung oder mit Zustimmung der SMAD Rechtsverordnungen mit Gesetzeskraft erlassen“ könnten. Die Provinzialregierung schlug daher vor, daß die Verordnungentwürfe der Zentralverwaltungen zunächst mit den zuständigen Länderministerien beraten und anschließend in den Landtagen beschlossen werden sollten ${ }^{103}$. Die Landesregierung in Weimar schloß sich, nachdem sie ein Gutachten des Oberverwaltungsgerichts Jena ${ }^{104}$ eingeholt hatte, am 7. Februar der Auffassung der Provinzialregierung in Halle an: Die Besatzungsmacht habe zwar weiterhin das Recht, in die Gesetzgebung des Landes „auch durch Befehle einzugreifen“, die Verordnungen der Zentralverwaltungen würden hingegen nicht mehr anerkannt, auch wenn diese mit „Bestätigung“ einer Dienststelle der SMAD erlassen worden seien. Daraus folgerte sie: „Aufbau und Befugnisse der Zentralverwaltungen sind mit den jetzt in Kraft getretenen demokratischen Länderverfassungen in Einklang zu bringen. Sie sind durch gemeinsame Vereinbarungen der Länder und Provinzen festzulegen und durch die Landtage in Gesetzesform zu bestätigen. Die Spitzen der Zentralverwaltungen sind unter Bestätigung durch die SMAD von den Ländern und Provinzen selbst zu bestimmen."105 Wollte die Regierung in Halle demnach, nur' den Schwerpunkt des Gesetzgebungsverfahrens unter weitgehender Ausschaltung der Berliner Verwaltungen auf die Landtage und Landesregierungen verlagern, strebte das Kabinett in Weimar eine vollständige Umkehrung des Verhältnisses zwischen Ländern und Zentralverwaltungen an.

Wenngleich derartige Vorstellungen unrealistisch waren, zeigen sie doch, mit welcher Konsequenz Sachsen-Anhalt und Thüringen das Gesetzgebungsrecht ihrer Landtage zu nutzen gedachten. Dies änderte sich auch nicht, nachdem die Zentralverwaltungen ihre - von der SMAD-Rechtsabteilung bestätigten - Verordnungen ab dem 24. Mai 1947 im Zentralverordnungsblatt veröffentlichten. So vertrat das Justizministerium in Halle die Auffassung, daß die Anordnung über die Zuständigkeit im gerichtlichen Verfahren vom 8. Mai trotz ihrer Veröffentlichung im Zentralverordnungsblatt nicht in Sachsen-Anhalt rechtswirksam sein könne, was von der DJV unter Berufung auf ihre Ermächtigung durch die SMADRechtsabteilung bestritten wurde ${ }^{106}$. Zu einer ähnlichen Auseinandersetzung kam es mit Thüringen im Hinblick auf die Verordnung über die Zuständigkeit der

103 Provinzialregierung Sachsen-Anhalt an DJV, 16. 1. 1947, BAB, DP1 VA Nr. 6871. Nach einem Kabinettsbeschluß der Provinzialregierung vom 21.1. 1947 wurde dieses Schreiben von allen Kabinettsmitgliedern unterzeichnet und allen Zentralverwaltungen, Ministerpräsidenten und Fachministern zugesandt: Auszug aus der Niederschrift der Kabinettssitzung am 21.1. 1947, BAB, DP1 VA Nr. 6348.

104 Vgl. dazu Heil, Verwaltungsgerichtsbarkeit, S. 156.

105 Abschrift des Thüringer Regierungsbeschlusses, BAB, DP1 VA Nr. 6348.

${ }_{106}$ Chef der DJV an Justizminister Sachsen-Anhalt, 9. 5. 1947, Justizminister Sachsen-Anhalt an DJV, 24. 6. 1947, Chef der DJV an Justizminister Sachsen-Anhalt, 10. 7. 1947, Justizminister SachsenAnhalt an DJV, 25. 8. 1947, ebenda. 
Rechtspfleger vom 28. Juni, die ebenfalls nach Genehmigung durch die SMADRechtsabteilung im Zentralverordnungsblatt veröffentlicht wurde. Das thüringische Justizministerium bekundete gegenüber der DJV, daß „es zunächst noch der Inkraftsetzung der V.O. durch die zuständigen Stellen des Landes" bedürfe, bevor sie auch in Thüringen gelten könne ${ }^{107}$. Es forderte zudem am 23. Juli eine generelle "verfassungsrechtliche Klarstellung über die Rechtswirksamkeit“ der im Zentralverordnungsblatt publizierten Verordnungen. Darüber solle auf der kommenden Länderkonferenz beraten und abschließend ein SMAD-Befehl erlassen werden, der entweder klarstelle, „daß die im Zentralverordnungsblatt publizierten Verordnungen für die Zone ohne weiteres rechtswirksam" seien, oder das Übernahmeverfahren in den Ländern festlege ${ }^{108}$.

Da eine Klärung dieser Frage auch im Interesse der DJV lag, griff man dort die Anregung aus Thüringen auf. Die zuständige Abteilung riet jedoch davon ab, das Problem direkt auf die Tagesordnung der bevorstehenden Länderkonferenz zu setzen ${ }^{109}$. Die DJV wollte vielmehr zunächst die SMAD-Rechtsabteilung zu einer Stellungnahme bewegen. Daher erarbeitete sie eine ausführliche „Denkschrift zur Frage der Rechtsverbindlichkeit der Anordnungen der Deutschen Justizverwaltung", die mit Schreiben vom 16. Oktober in Karlshorst vorgelegt wurde110. In dem Memorandum ging sie auf die Auseinandersetzungen mit Sachsen-Anhalt und Thüringen sowie auf ähnliche Konflikte mit Sachsen und Brandenburg ein. Während die sächsische Landesregierung vor allem durch gesetzgeberische Sondermaßnahmen die DJV provozierte, lehnte das brandenburgische Justizministerium die Regelung zur Anwendung der Strafprozeßordnung ab, die auf der Länderkonferenz am 11./12. April 1947 beraten worden war. Diese Weigerung und andere Anordnungen der Justizverwaltung in Brandenburg ${ }^{111}$ waren nach Auffassung der DJV auf das Bestreben der Potsdamer Landesregierung zurückzuführen, „den Wirkungsbereich der Deutschen Justizverwaltung einzuschränken“. All diese Schwierigkeiten, so die Denkschrift, seien "grundsätzlicher Natur“: „Sie beruhen auf dem von den Ländern in der sowjetischen Besatzungszone vertretenen Standpunkt, daß die den Ländern verliehene Autonomie ihrer Natur nach keine Einschränkungen durch Rechtsverordnungen der in der Zone errichteten Verwaltungen vertrage." Dazu liege seit dem 13. August auch ein Rechtsgutachten des Oberverwaltungsgerichts Jena vor ${ }^{112}$. Beriefen sich die Länderregierungen auf

107 Verordnung über die Zuständigkeit der Rechtspfleger in: ZVOBl. 1947, S. 78-80; dazu DJV an Landes- u. Provinzialregierungen/Justizministerium, 3. 7. 1947; Justizministerium Thüringen an DJV, 9. 8. 1947, BAB, DP1 VA Nr. 6348.

108 Justizministerium Thüringen an DJV, 23. 7. 1947, ebenda.

109 Vermerk Guskis über die Dienstbesprechung der Abteilung V, 2. 8. 1947, BAB, DP1 VA Nr. 7354.

110 Chef der DJV an Chef der SMAD-Rechtsabteilung, 16. 10.1947, sowie die Denkschrift zur Frage der Rechtsverbindlichkeit der Anordnungen der Deutschen Justizverwaltung, BAB, DP1 VA Nr. 6348.

111 Es handelte sich dabei um Anordnungen zur Unterbindung jeden direkten Kontaktes zwischen den brandenburgischen Justizbehörden und der DJV.

112 Rechtsgutachten des Thüringer OVG vom 13.8. 1947, BAB, DP1 VA Nr. 6348. Es berief sich auf den Beschluß der thüringischen Landesregierung vom 7.2. und auf das Gutachten vom 6. 2. 1947 und enthielt keine neuen Argumente. Als „sehr schwerwiegend“ bezeichnete es den "staatspolitische[n] Einwand" gegen die unmittelbare Geltung der Berliner Verordnungen, "daß es im demokratischen Staat ein Unding wäre, wenn bürokratisch organisierte und nicht durch allgemeine Wahlen gebildete Behörden, wie die Berliner Zentralverwaltungen, gesetzgebende Befugnisse er- 
ihre demokratische Legitimierung und ihre parlamentarische Verantwortlichkeit, so war für die DJV das Besatzungsrecht und damit die Befehlsgebung der SMAD entscheidend. Da nach der Argumentation der DJV das Gesetzgebungsrecht der Länder „ein von der Gesetzgebungsbefugnis des Obersten Chefs der SMAD abgeleitetes Recht" war, ergaben sich daraus auch die Grenzen seiner Wirksamkeit. Eine Grenze stelle das Besatzungsrecht selbst dar: Landesrecht dürfe weder zu den Anordnungen des Kontrollrats noch zu den Befehlen der SMAD in Widerspruch stehen. Des weiteren habe die Besatzungsmacht den Ländern das Gesetzgebungsrecht nur „für ihr Landesgebiet“ verliehen und ihr eigenes Recht zu zentraler Gesetzgebung in der SBZ nicht eingeschränkt. Da die SMAD jedoch mit Befehl Nr. 17 Zentralverwaltungen zur Durchführung ihrer Verwaltungsmaßnahmen errichtet habe, müsse ,jede Rechtsverordnung einer deutschen Zentralverwaltung, die mit Wissen und Willen der SMAD ergeht, als ein Ausfluß zentraler Rechtssetzung angesehen werden“. Dabei spiele es für die Rechtsverbindlichkeit keine Rolle, ob die Rechtsakte aus Berlin in Befehlsform ergingen oder auf andere Weise bestätigt würden.

Im Anschluß an die Übergabe der Denkschrift in Karlshorst am 22. Oktober arbeitete Rosenthal-Pelldram noch einen Befehlsentwurf für den Obersten Chef der SMAD aus, mit dessen Hilfe die DJV die „Unklarheiten, die bei dem Erlaß von Verordnungen, Anordnungen und Verfügungen der Deutschen [Zentral]Verwaltungen hervorgetreten" seien, beseitigen wollte. Der Befehl sollte festlegen, daß allen von den Zentralverwaltungen „in Ausübung ihrer Funktionen gemäß den Direktiven der entsprechenden Abteilungen der SMAD“ erlassenen Rechtsakten unmittelbare Geltung zukomme, daß die im Zentralverordnungsblatt veröffentlichten Verordnungen eine Woche nach ihrer Verkündung in Kraft treten würden, daß das Zentralverordnungsblatt ein „Mitteilungsblatt im Sinne des Artikel III des Kontrollratsgesetzes Nr. 38“113 sei und daß ,in Ausübung der ihnen zustehenden Leitungsbefugnis“ den Zentralverwaltungen „auch der unmittelbare Verkehr" mit den örtlichen Dienststellen in den Ländern freistehe ${ }^{114}$. Sowohl die Denkschrift als auch der Befehlsentwurf sollten zu einer möglichst umgehenden Klarstellung des Verordnungsrechts der Zentralverwaltungen im Sinne der DJV führen.

Eine Reaktion der SMAD-Rechtsabteilung auf die Denkschrift und den Befehlsentwurf blieb freilich aus. Die DJV mußte sich also darauf beschränken, weiter Fälle zu sammeln, in denen die von den Zentralverwaltungen gegenüber den Ländern beanspruchten Vorrechte in Frage gestellt wurden. Am 6. Januar 1948 erstattete Rosenthal-Pelldram Major Nikolajew in Karlshorst Bericht über das seit

hielten, die vor den Gesetzen der gewählten Landtagsparlamente sogar noch den Vorrang hätten“. Vgl. dazu auch Heil, Verwaltungsgerichtsbarkeit, S. $157 \mathrm{f}$.

${ }^{113}$ Artikel III des Kontrollratsgesetzes Nr. 3 vom 30. 10. 1946 lautete: „In allen Fällen, in denen nach den Bestimmungen einer gesetzlichen Vorschrift die Veröffentlichung in dem Deutschen Reichsanzeiger erforderlich oder vorgesehen ist, ist diese Veröffentlichung durch Einrückung in ein Mitteilungsblatt zu bewirken, das von der Alliierten Kontrollbehörde zu bezeichnen und bis zu einer solchen Bezeichnung von dem Zonenbefehlshaber zu bestimmen ist." Amtsblatt des Kontrollrats, Nr. 11, 31. 10. 1946, S. 221.

114 Befehlsentwurf mit der Paraphe Rosenthal-Pelldrams und handschriftlicher Datierung auf den 27. 10. 1947, BAB, DP1 VA Nr. 6384. 
Oktober 1947 gesammelte Material und betonte abschließend nochmals „das Interesse der Deutschen Justizverwaltung a) an dem Erlaß eines Befehls, b) an einer Sicherstellung ihrer Koordinierungsbefugnisse auf dem Gebiete der Gesetzgebung [und] c) an einer Klarstellung des Statutes" ${ }^{115}$. Zwar äußerte sich Nikolajew im Verlauf der Unterredung nicht zu den Wünschen der DJV; indem er aber zwei Tage später ein Schreiben der DJV an den thüringischen Justizminister Külz billigte ${ }^{116}$, gab die SMAD-Rechtsabteilung erstmals indirekt zu erkennen, daß sie die Rechtsauffassung der DJV befürwortete. Denn der Brief, der sich auf eine Aussprache zwischen Rosenthal-Pelldram und Külz am 11. Dezember 1947 bezog, enthielt wörtlich jene Punkte aus der Denkschrift vom 16. Oktober, die man der weitgehenden Auslegung der Länderrechte entgegengestellt hatte ${ }^{117}$.

Eine endgültige Regelung des Problems stand indes immer noch aus. Erst sieben Monate später, als die entscheidenden Weichen hin zu einer Zentralisierung des Justizwesens gestellt worden waren, forderte Nikolajew die DJV auf, „ihm schriftlich Fälle mitzuteilen, in denen die Länder die Veröffentlichungen von Anordnungen, Verfügungen usw. der Deutschen Justizverwaltung im Zentralverordnungsblatt nicht für genügend zur Inkraftsetzung derselben erachtet haben, sondern dies von der Veröffentlichung im jeweiligen Landesgesetzblatt abhängig machen“. Den gegenwärtigen Zeitpunkt, so fügte er hinzu, erachte er „für einen Vorstoß in dieser Richtung für günstig "118. Weiß teilte daraufhin nach einer Sichtung der einschlägigen Akten Melsheimer mit, daß derartige Fälle in letzter Zeit nicht mehr bekannt geworden seien, und stellte die Frage, ob dennoch ein Vorstoß bei der SMAD-Rechtsabteilung unternommen werden sollte. Melsheimer erwiderte lakonisch: „Nein: die Länder haben sich offensichtlich gebeugt.“119

Inzwischen waren die meisten Zentralverwaltungen in der DWK zusammengefaßt worden, der mit Befehl Nr. 32 vom 12. Februar 1948 das Recht eingeräumt wurde, für alle deutschen Organe verbindliche Verfügungen zu erlassen ${ }^{120}$. Auch die noch selbständigen Zentralverwaltungen (DVdI, DVV, DJV) hatten eine Ausweitung ihrer Kompetenzen erfahren, so daß dem Problem bezüglich des Gesetzgebungsrechts der DJV nunmehr nur noch eine untergeordnete Bedeutung zukam. Die Länder revidierten angesichts dieser Änderungen von sich aus ihre intransigente Haltung in der Verordnungsfrage: Die thüringische Regierung etwa hob am 14. Juni 1948 ihren Beschluß vom 7. Februar 1947 förmlich auf121. Die SMAD-Rechtsabteilung sah folglich den Zeitpunkt zu einer Intervention erst dann als "günstig“ an, als die Kompetenzfrage bereits geklärt war. Das ganze Jahr 1947 hatte sie sich jedoch, sehr zum Ärger der DJV, nicht in der Lage gesehen, zu

115 Vermerk über die Rücksprache Rosenthal-Pelldrams bei Nikolajew am 6. 1. 1948, ebenda.

${ }^{116}$ Den Entwurf des Schreibens hatte Rosenthal-Pelldram am 6. 1.1948 vorgetragen; die Billigung des Schreibens wurde von Nikolajew am 8.1.1948 telefonisch mitgeteilt, Vermerk Rosenthal-Pelldrams, 9. 1. 1948, ebenda.

117 Chef der DJV an Justizminister Külz, 8. 1. 1948, ebenda.

118 Vermerk über eine Unterredung mit Nikolajew, 13. 8. 1948, BAB, DP1 VA Nr. 11, Bl. 150.

119 Vermerk von Weiß für Melshcimer, 9. 10. 1948; Antwort Melsheimers, 11. 10. 1948, BAB, DP1 VA Nr. 6348.

120 Gedruckt in: Um ein antifaschistisch-demokratisches Deutschland, S. 585 f. Dies bedeutete jedoch nicht, daß die SMAD nun nicht mehr in die Angelenheiten der Wirtschaftskommission eingriff: vgl. dazu Foitzik, Sowjetische Militäradministration in Deutschland, S. 388 f.

121 Heil, Verwaltungsgerichtsbarkeit, S. 159. 
dem Problem Stellung zu nehmen. Von der wahrscheinlich deutschlandpolitisch bedingten Unsicherheit in der SMAD profitierten in dem Konflikt zwischen Zentralismus und Föderalismus die Länder, deren relative Selbständigkeit nach 1947 jedoch Zug um Zug abgebaut werden sollte.

Der Konflikt zwischen Zentralismus und Föderalismus war in der ambivalenten sowjetischen Besatzungspolitik von vornherein angelegt. Einerseits sprach die SMAD den Ländern das alleinige Gesetzgebungsrecht zu, andererseits benötigte sie deutsche Zentralverwaltungen als gesamtzonale Hilfsorgane ihrer Fachabteilungen in Berlin-Karlshorst. Schiffer war nicht zuletzt mit Blick auf die Umsetzung der Justizreform an einer klaren Vorrangstellung der DJV gegenüber den Landesjustizverwaltungen gelegen und drängte daher die SMAD-Rechtsabteilung wiederholt, ihm entsprechende Vollmachten zu erteilen oder zumindest eindeutig auf seiten der Zentralverwaltung Stellung zu beziehen. Die Rechtsabteilung verhielt sich jedoch widersprüchlich: Sie verweigerte ihm das Weisungsrecht, genehmigte ein Statut mit weitreichenden Kontrollrechten, das jedoch stets als „vorläufig" bezeichnet wurde, beauftragte die DJV mit der Vereinheitlichung der Landesjustizabteilungen, ließ diese dann aber mit ihren Plänen in der Luft hängen, um im August 1946 die Frage doch im Sinne der Länder zu entscheiden. Dabei handelte es sich auch um einen Sieg der SED-Justizabteilung, die sich mit ihrem Vorhaben, die Justizverwaltung aus (personal-)politischen Gründen bei der Justizabteilung zu konzentrieren, durchgesetzt hatte. All dies stärkte die Landesjustizverwaltungen gegenüber der DJV, die auch mit dem Instrument der sogenannten Länderkonferenzen nicht in der Lage war, die Gesetzgebung effektiv zu koordinieren. 1947 schließlich erreichten die Auseinandersetzungen einen Höhepunkt, vor allem als die Länder sich weigerten, die Rechtsverbindlichkeit der im Zentralverordnungsblatt veröffentlichten Verordnungen anzuerkennen. Die Landesregierungen fühlten sich zusätzlich gestärkt, da sie seit den Wahlen vom Herbst 1946 demokratisch legitimiert waren, während die DJV sich lediglich auf Besatzungsrecht berufen konnte. Auch in diesen Streit griff Karlshorst nicht zugunsten der DJV ein, was wohl auf Unentschiedenheit, aber auch auf deren Überlastung mit anderen Aufgaben zurückzuführen ist. Insgesamt sind die Jahre 1945 bis 1947 daher von einer relativen Selbständigkeit der Landesjustizverwaltungen gegenüber der Zentrale gekennzeichnet ${ }^{122}$; deren Handlungsspielraum war freilich durch die Kompetenzen der regionalen Militärverwaltungen sowie der dortigen Innenbehörden mit ihren Polizeiapparaten erheblich eingeschränkt. 